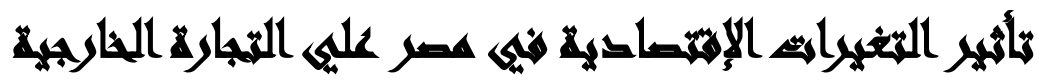

\section{[Y I]}

\author{
محمد كامل ريحان(')- سهام أحمد عبد الحميد(r)- عمرو عبدالحميد رفعت(r) عمداد

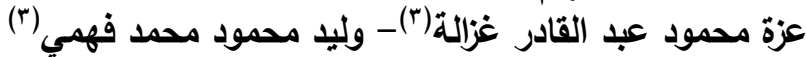

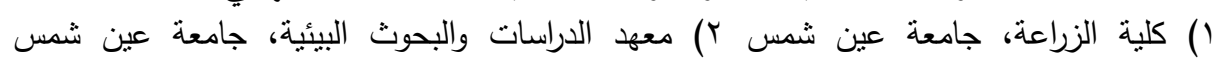
r مركز بحوث الصحراء

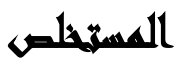

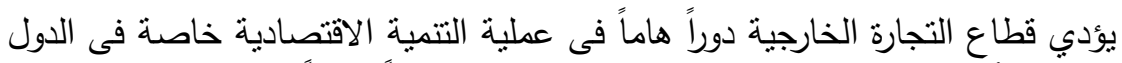

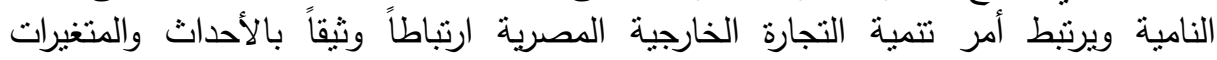

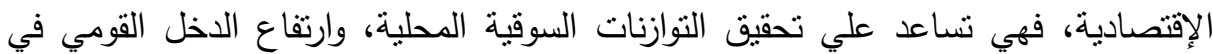

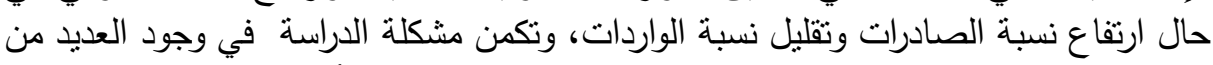

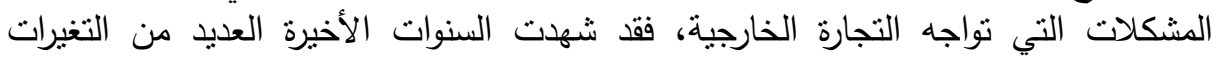

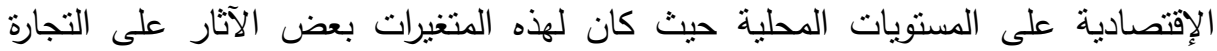

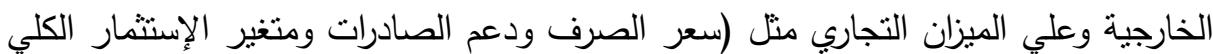

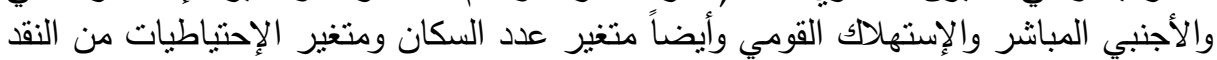

وتهدف الدراسة إلي التعرف علي أهم المتغيرات الإقتصادية التي تؤثر علي التجارة

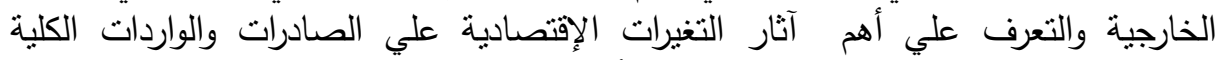

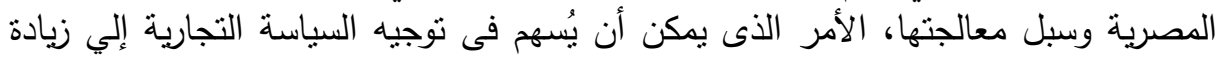

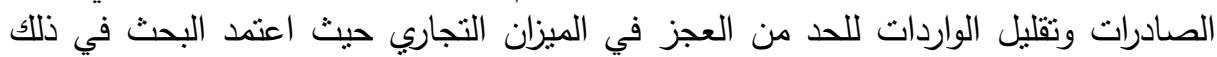

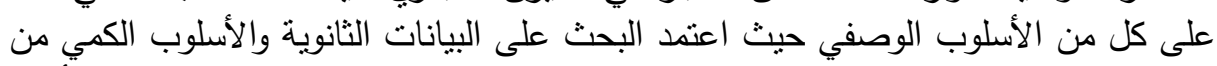

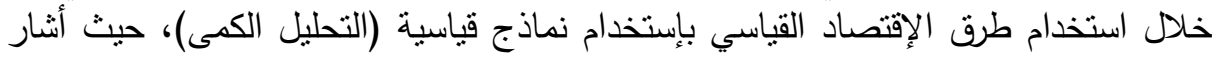

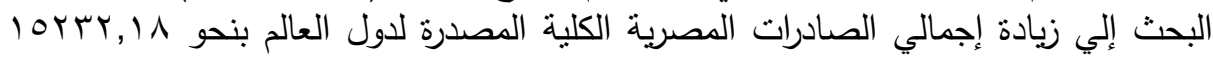

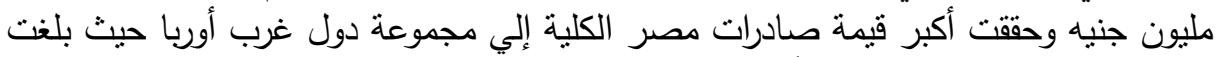

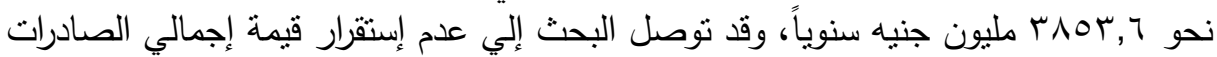

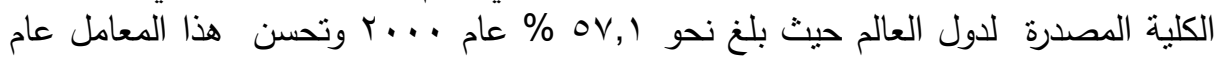

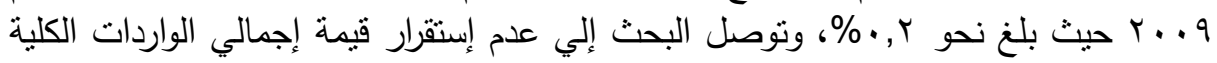

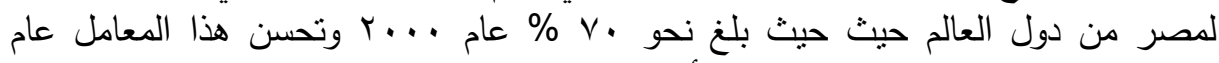

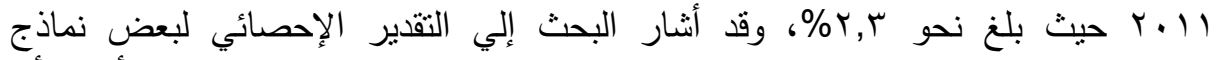

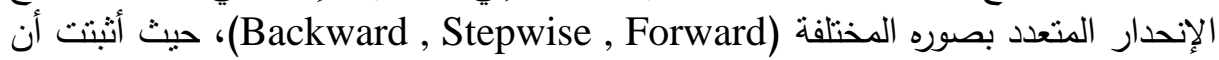

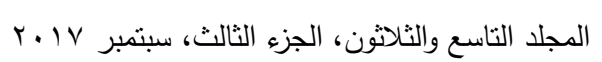


المتغيرات الإقتصادية ذات التأثير الإيجابي علي الصادرات المصرية الكلية هي سعر الصرف

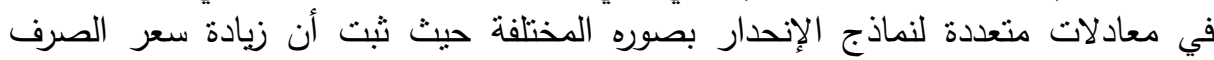
يساعد في زيادة الصادرات الكلية المصرية وكذلك متغير دعم الصادية لإدرات ومتغير الإستثمار

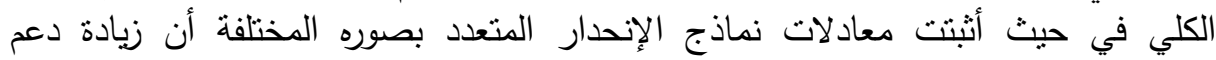
الصادرات والإستثمار الكلي والأجنبي المباشر يساعدان في زيادة الصادرات الكلية المصات العصرية،

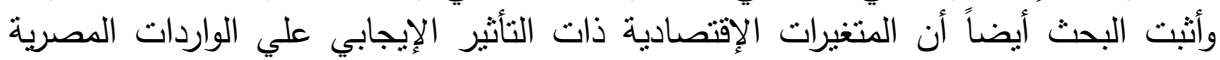

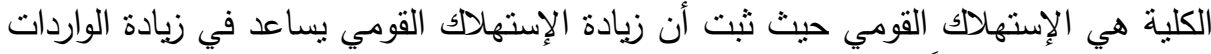

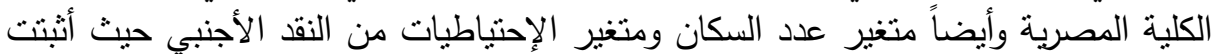

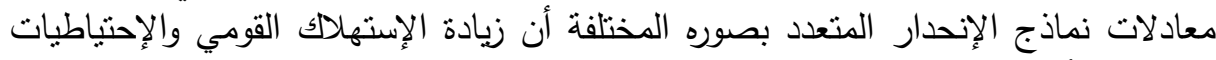
من النقد الأجنبي يساعدان في زيادة الواردات المئدرد المصرية الكلية.

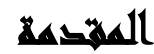

يلعب قطاع التجارة الخارجية (عاطف جودة) دوراً هاماً فى عملية التتمية الاقتصادية خاصة فى الدول النامية، حيث تعتبر التجارة الخارجية من أهم ميادين السياسة الإقتصادية نظراً لتأثيرها الكبير على النطور الإقتصادي سلباً أو إيجاباً، وأهداف سياسة التجارة الخارجية

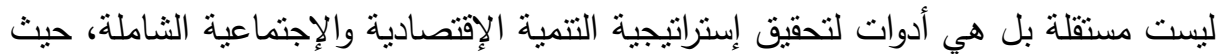
يعتبر الميزان التجاري لأي لدولة المرآة التي تعكس مستوى وخصائص إقتصاد هذا البلد

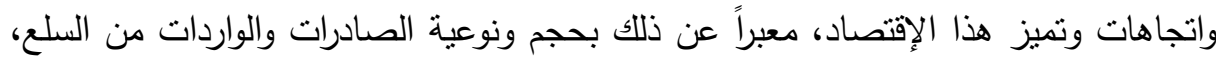
فلقد تأثرت التجارة الخارجية في مصر بالعديد من التغيرات الإقتصادية التي تؤثر سلباً وإيجابًا

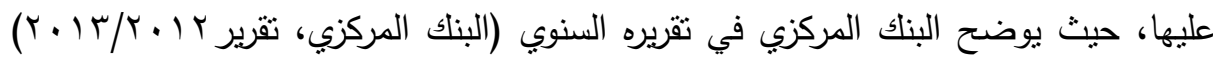
أن الأزمة الاقتصادية التي تعانيها تتجلى مصر في جوانب عدة، حيث انخفضت احتباطيات

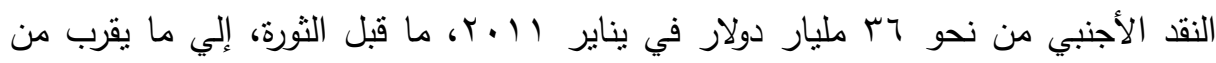

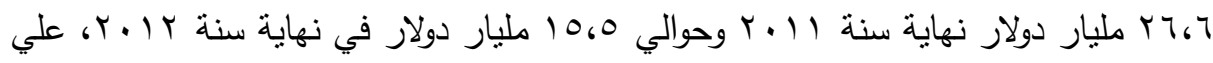

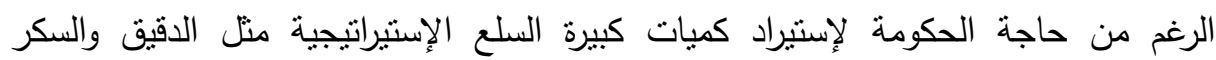

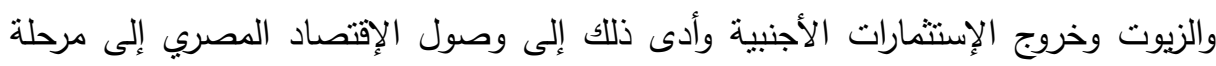

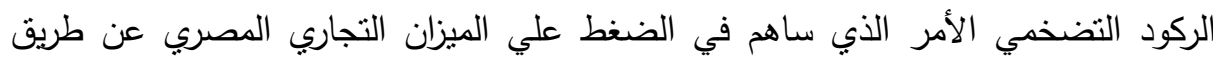
زيادة الواردات حتي تفي الدولة باحتياجاتها، وبالنسبة لصافى الإحتياطيات الدولية لدى البنكي 


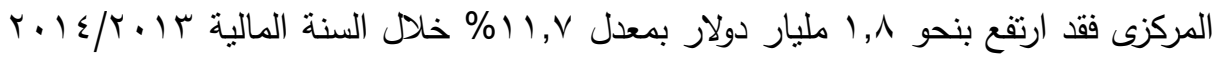

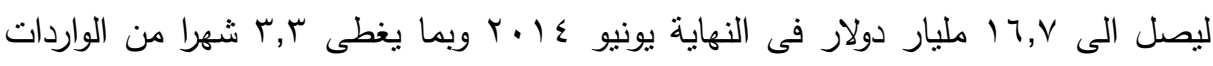

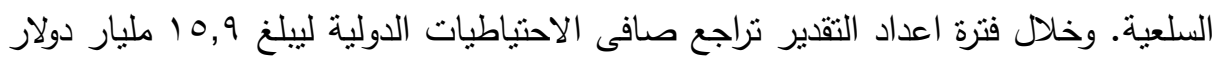

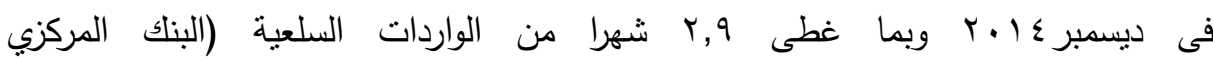

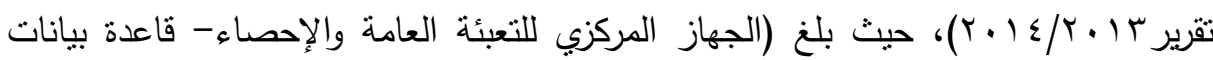

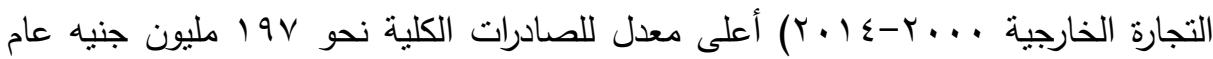

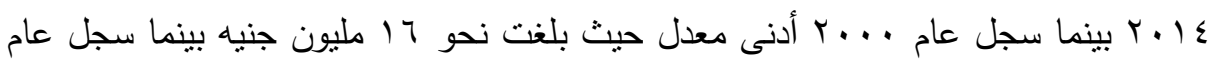

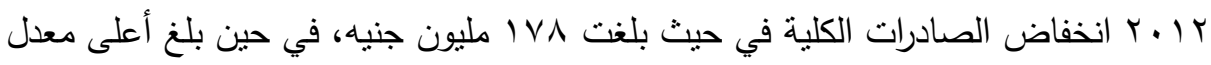

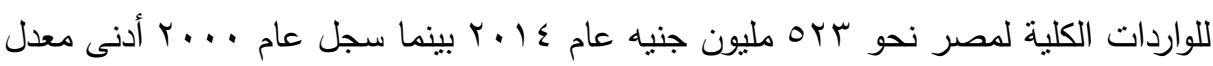
حيث بلغت نحو هـ مليون جنيه وتنين أن أعلى معدل للميزان التجاري المصري (الفرق بين

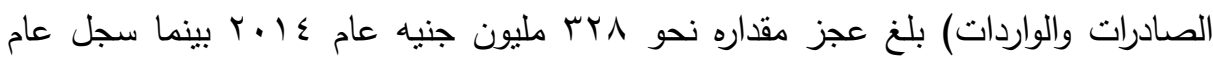

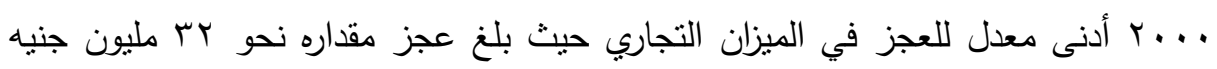

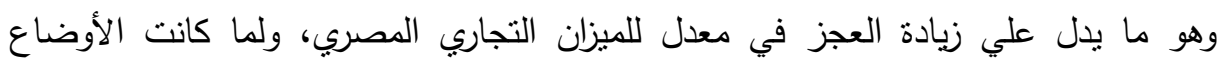

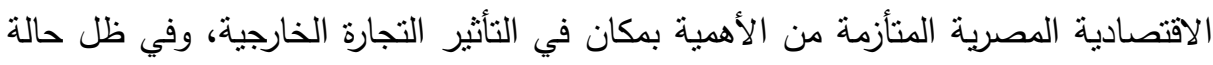

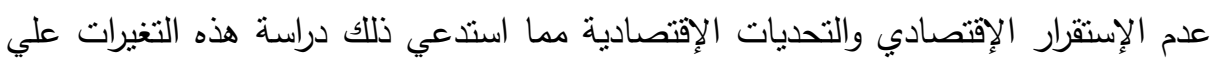

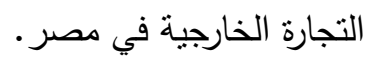

\section{And ILan}

تتمنل مشكلة الدراسة في وجود العديد من المشكلات التي نواجه التجارة الخارجية فقد شهدت السنوات الأخيرة العديد من التغيرات الإقتصادية على المسنويات المحلية حيث كان

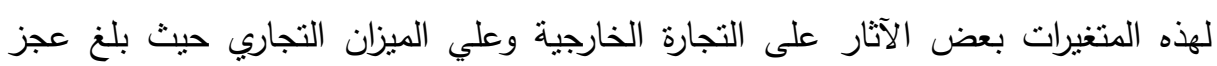

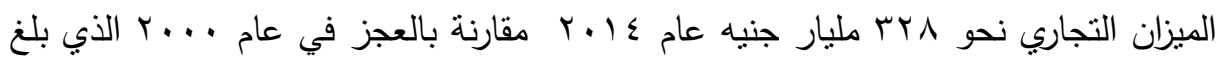

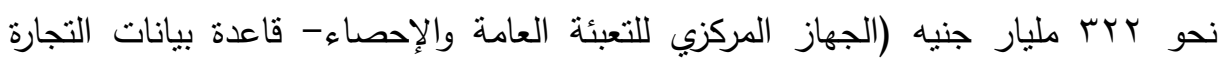

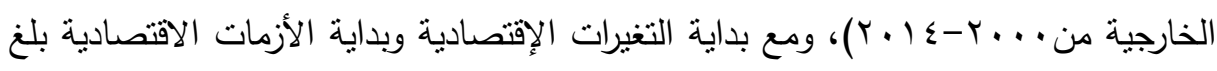

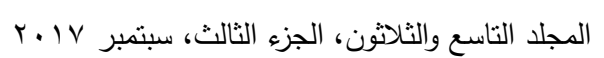




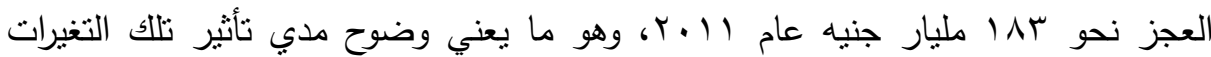
الإقتصادية علي الميزان التجاري.

تعود الأزمة الاقتصادية في مصر لعدم الاستقرار الاقتصادي وما يرتبط به من نتائج

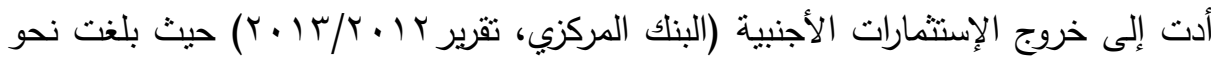

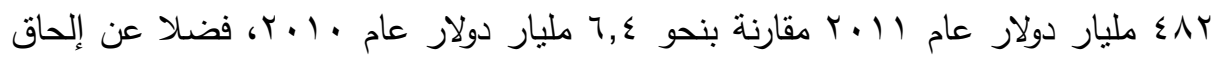

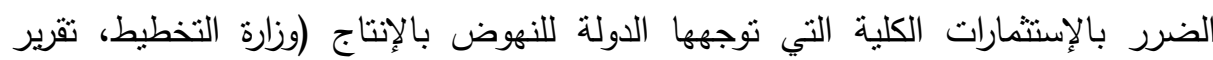

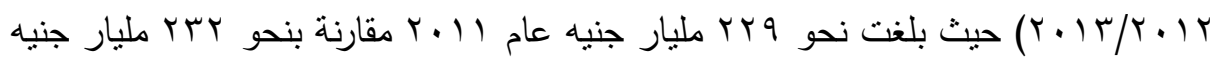

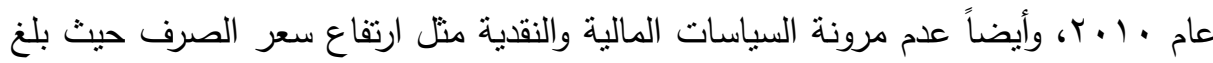

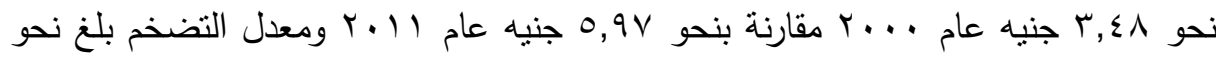

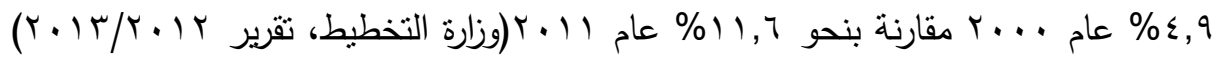

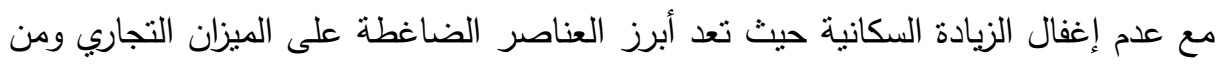

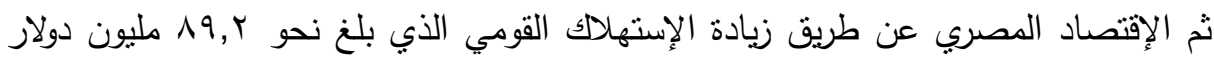

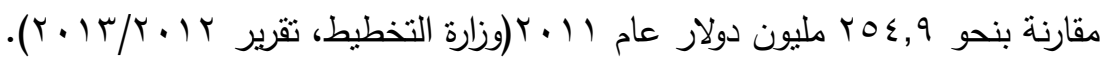
وتتجلى التغيرات الإقتصادية التي تعانيها مصر في جوانب عدة، فقد انخفض إحتياطي

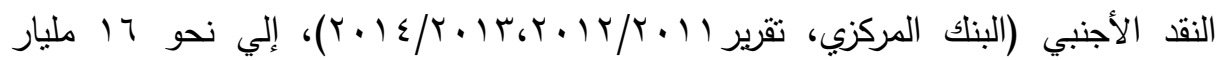

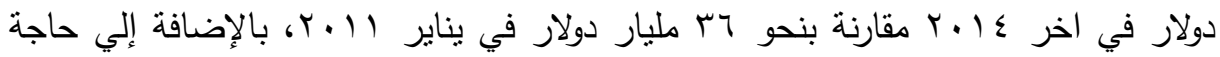

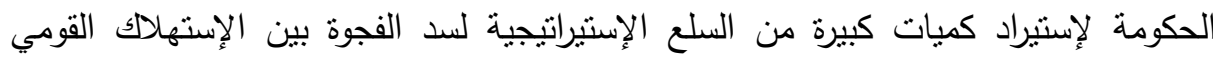

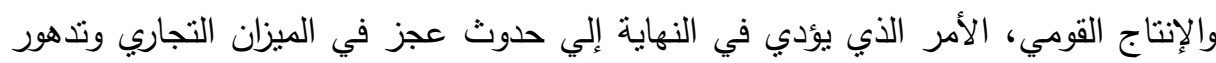
في معدلات التبادل التجاري لمصر مما يشكل عبئا" ثقيلا" علي ميزان المدفوعات ومن ثئ

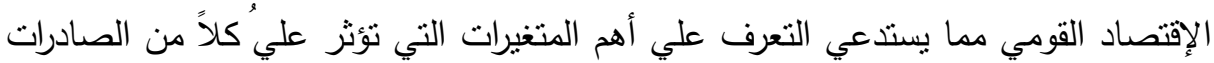




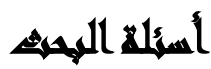

ويمكن طرح الهذف الرئيسي على شكل تساؤل ألا وهو. هل تأثرت التجارة الخارجية الدصرية بالتغيرات الإقتصادية الني حدثت في مصر ؟ وينبثق أسئلة فرعية وهي:

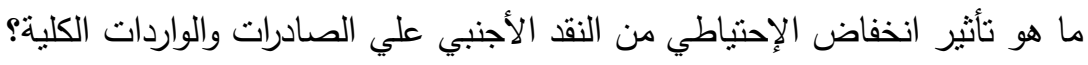

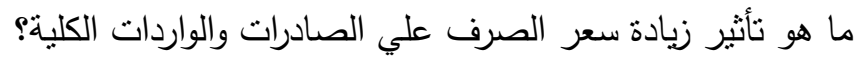

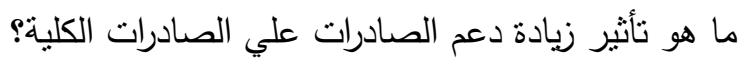

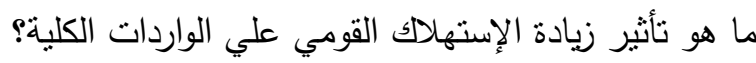
ما هو نأثير زيادة الإنتثمار القومي والإنتثمارت الأجنيبة علي الصادرات الإدات والواردات الكلية؛؟ ما هو نأثير الإثفاقيات التجارية علي الصادرات والواردات الكلية؟ الإنج

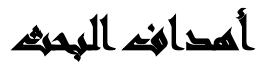

تهذف الدراسة إلى التعرف علي أهم الهتغيرات الإقتصادية التي تؤثر علي التجارة

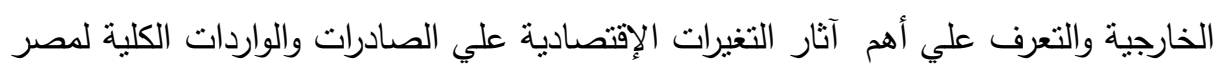

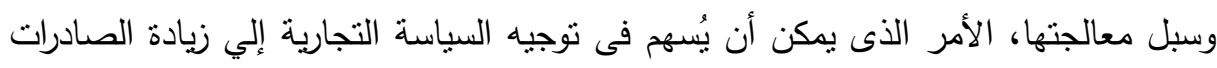

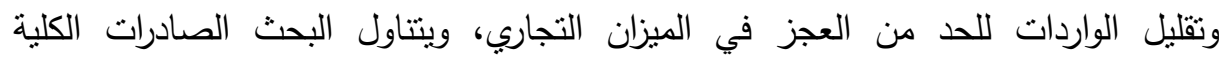

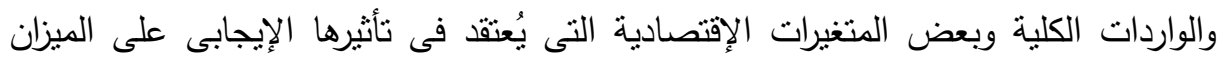

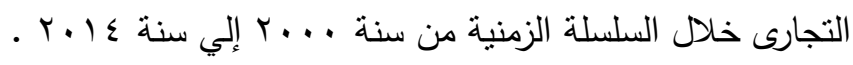

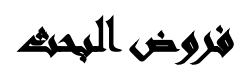

الفرض البديل الأول توجد علاقة جوهرية ذات دلالة إحصائية بين زيادة تكاليف الانتاج

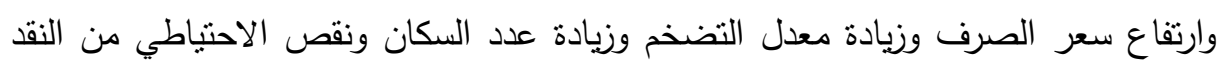

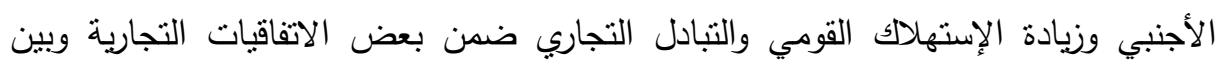

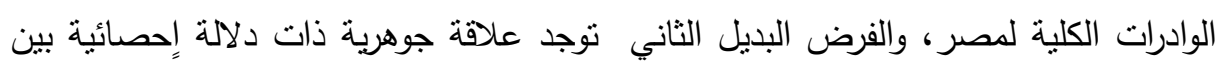

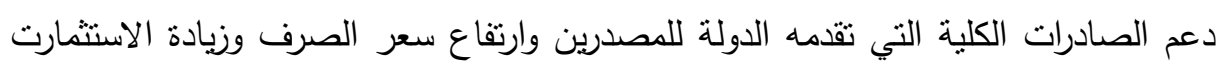


الكلية والأجنبية المباشرة وزيادة الناتج المحلي الكلي وبعض الاتفاقيات التجارية ونسب

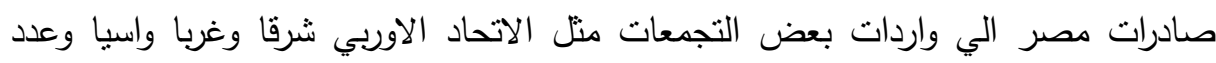
سكان تلك المناطق وبين الصادرات الكلية المصرية.

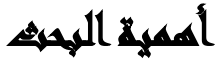

وتعكس التجارة الخارجية بصفة عامة تطور الصادرات والواردات مع العالم الخارجى وبالتالى تؤثز على كل من الإنتاج والإستهلاك والإستثمار وتؤدى إلى انتعاش أو انكماش

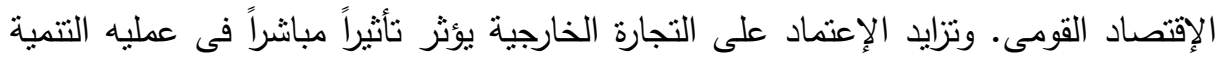
الإقتصادية حيث تكون الصادرات مصدراً لتوفير النقد الأجنبى اللازم لتمويل عمليات شراء لإدراء

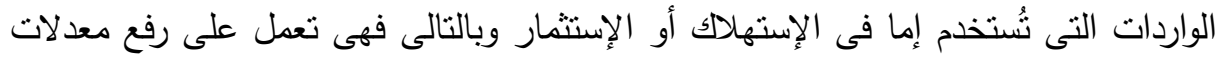

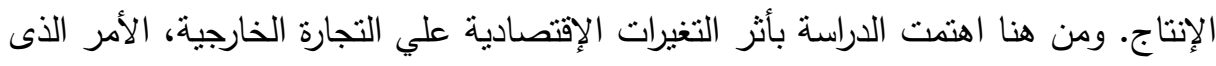

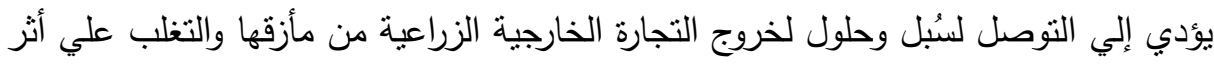
التغيرات الإقتصادية.

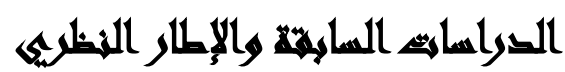

بينت دينا فاروق محمود عناني، إمكانية التكامل العربي في ضوء أهم المتغيرات

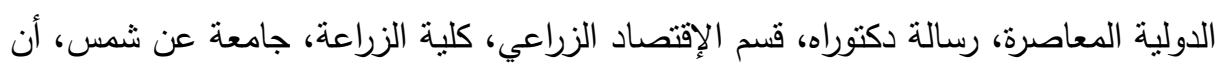

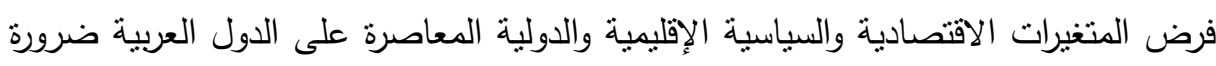

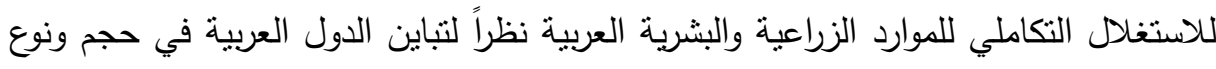

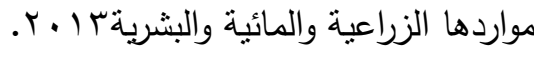

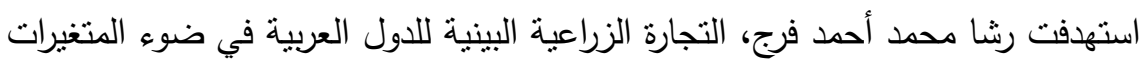
الدولية المعاصرة رسالة دكتوراه، قسم الإقتصاد الزراعي، كلية الزراعة، جامعة عين

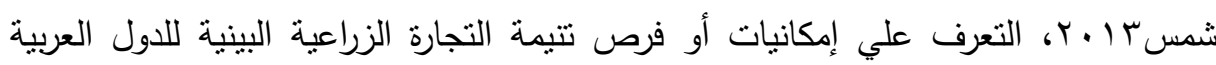
لإحداث تكامل عربي ودراسة أثز المتغيرات الدولية عليها حيث تتاولت الوضع الراهن للتجارة 
الخارجية العربية الكلية وتتاولت أيضا التجارة البينية الزراعية الكلية والبينية الزراعية العربية وتبين من الملامح الرئيسية للتجارة العربية الكلية والزراعية والتجارة الزراعية البينية العربية

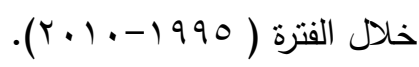

أثنارت شيماء محمد نجيب الثافعي، دراسة تحليلية لآثار المتغيرات الإقتصادية العالمية

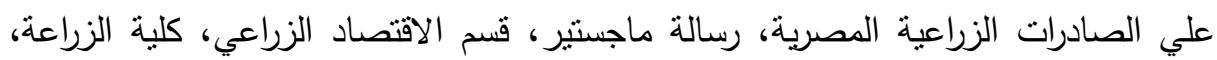

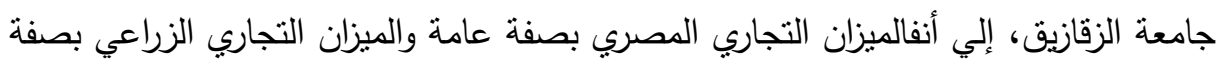

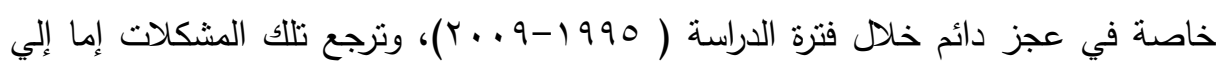
عوامل داخل القطاع الزراعي علي مستوي الإقتصاد منل الأسعار التصديرية وقيم الصادرات

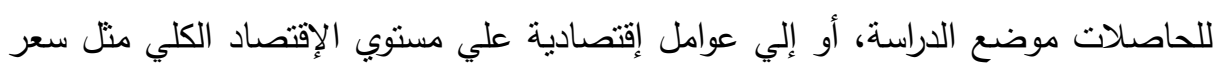

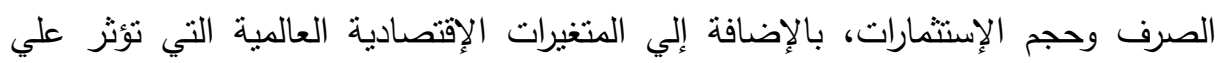

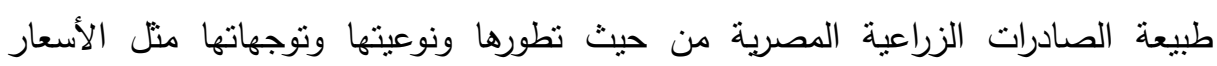
العالمية للسلعة.

بين أحمد محمد عبدالمقصود، دور دعم الصادرات في تحسين أداء الميزان التجاري

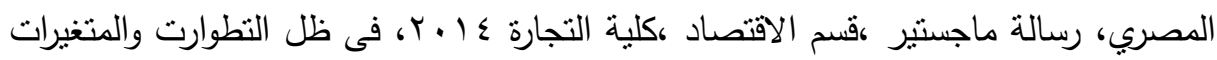

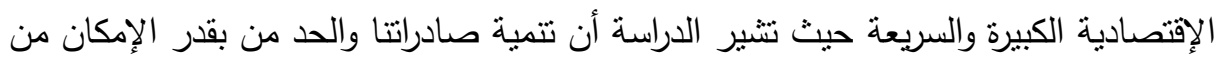

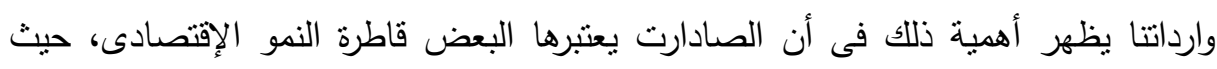

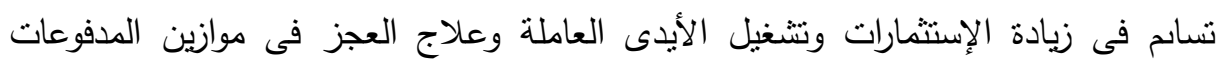

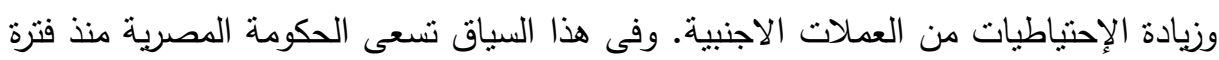

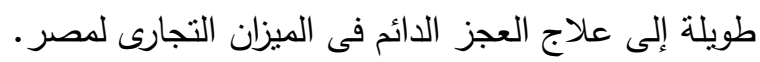
استهدفت هويدا السيد حسن محمد، النظام التجاري الدولي الجديد وانعكاساته علي سياسات التجارة الخارجية الكلية والزراعية المصرية وذلك من خلال التعرف علي النظام التجاري الدولي في إطار منظمة التجارة العالمية وتتاولت ايضا تحليل أداء سياسات التجارة الخارجية المصرية في إطار منظمة التجارة العالمية، وتتاولت سياسات التجارة الدولية الخارجية المصرية مع التركيز علي القطاع الزراعي في إطار اتفاقيات التجارة الاقليمية جيث تطرقت 
لأهم الاتفاقيات التجارية التي وقعتها مصر سواء علي المستوي الاقليمي او المستوي الثنائي

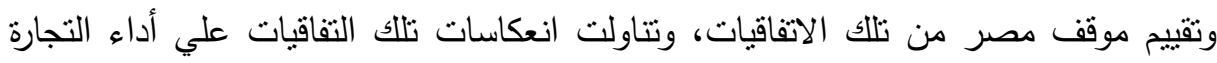

الخارجية الكلية والزراعية المصرية خلال فتريتين قبقل وبعد انضمام مصر للاتفاقية.

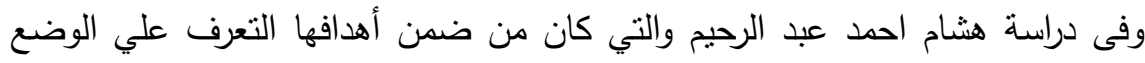
الراهن وملامح التجارة الخارجية الزراعية المصرية، ودراسة الآثار الاقتصادية للمتغيرات العالمية علي صادرات أهم السلع الزراعية المصرية، تبين أن كل من إيطاليا وفرنسا أهم أسواق الاتحاد الأوروبي للقطن المصري، حيث بلغ مجموع منوسط كمية وقيمة الصادرات

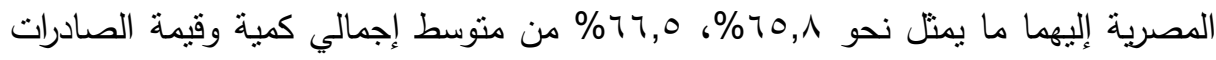

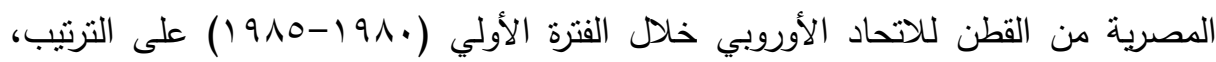

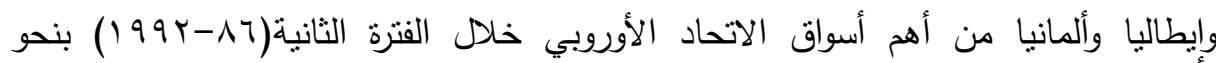

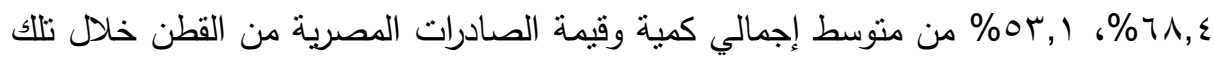

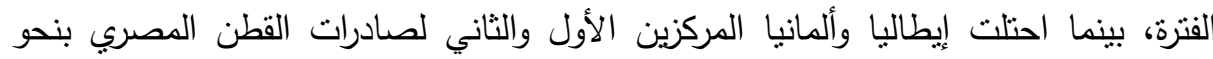

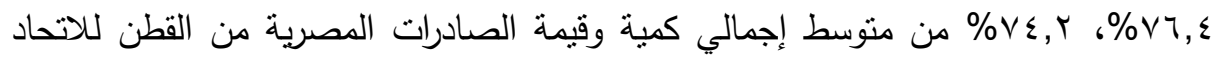

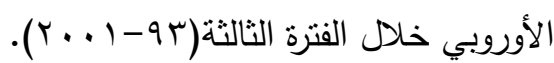
كما اهتم فهي علي مدكور بإلقاء الضور علي وضع التجارة الخارجية الزراعية المصرية والمحاور التي بذلت لتقليل العجز في الميزان التجاري والزراعي خلال الفترة

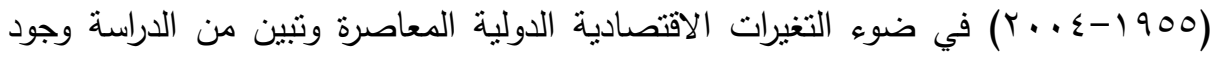
عجز في الميزان التجاري والزراعي والغذائي المصري طول فترة الدراسة، وتتاول اتفاقيات مناطق التجارة الحرة المصرية وبعض الدول العربية وعلاقة مصر التجارية والزراعية بهذه الدول والاتجاه العام لنطور قيمة الصادرات والواردات الكلية والزراعية بين مصر ودول مناطق

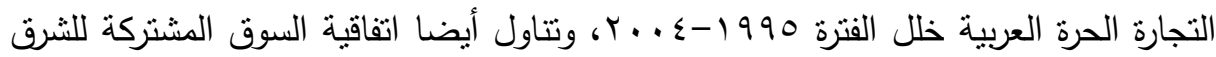
والجنوب الافريقي "الكوميسا" وعلاقة مصر التجارية والزراعية بدول الكوميسا والاتجاه العام لتطور قيم الصادرات والواردات العامة والزراعية بين مصر ودول الكوميسا حيث تبين وجود 
عجز في الميزان التجاري والكلي خلال فترة الدراسة.ونتاول أيضا علاقة مصر التجارية والزراعية مع كل دولة من دول الاتحات الاوربي الخمسة والعشرون.

استهدفت رحاب سعيد إبراهيم أحمد، تحليل هيكل التجارة الخارجية المصرية عامة داتهة

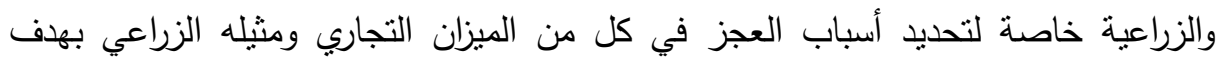
التعرف علي التغيرات في هيكل التجارة الخارجية الزراعية المصرية مع تقدير لأثر المتغيرات

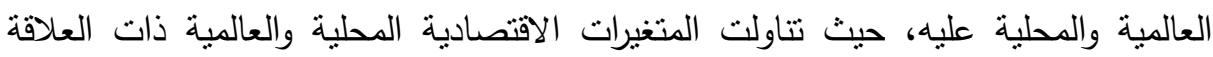
بهيكل التجارة الخارجية المصرية منها المؤسسات العاملة في مجال التجارة الخارجية المصرية

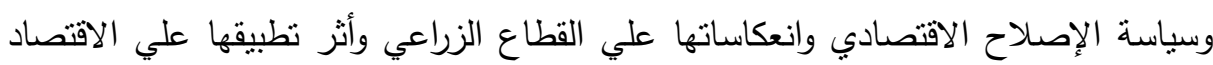
المصري بصفة عامة والقطاع الزراعي بصفة خاصة، وتتاول التكتلات الاقتصادية العالمية

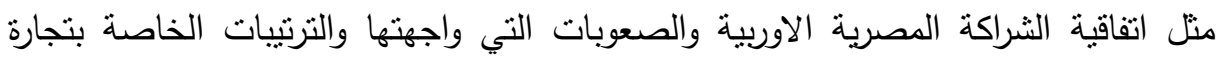

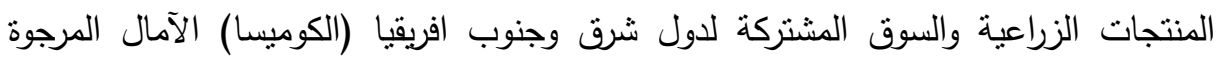
والتحديات التي نواجهها والسوق العربية المشتركة والمعوقات التي نواجه نطبيقها في مجال السلع الزراعية.

اهتم تامر محمد عبدالصادق السنتريسي، بالتعرف علي التوريع النوعي والجغرافي لكل

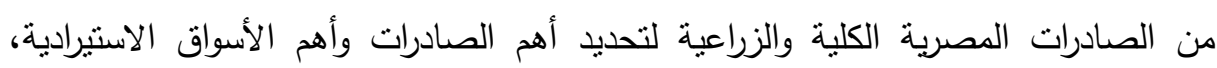

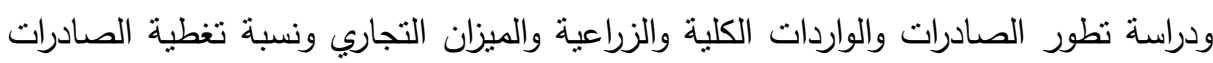

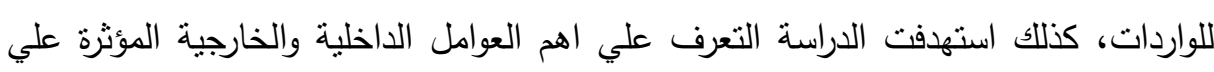

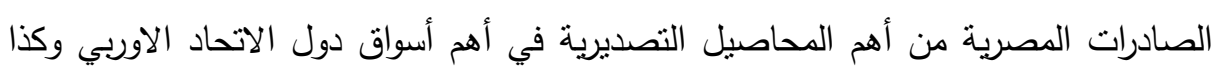
المركز التنافسي لتلك الصادرات.

كما أوضحت سعيد ابراهيم أحمد، الدراسة استهدفت تحديد اهم العوامل الاقتصادية

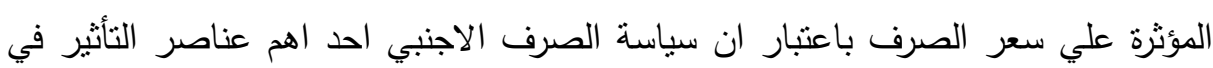

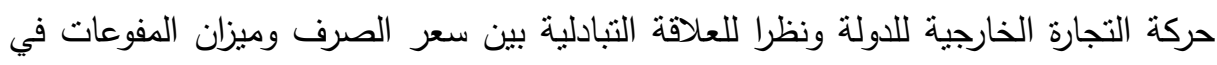
محاولة للتتبؤ بمتغيرات التجارة الخارجية والزراعية المساهمة في تحديد سعر الصرف. 


\section{مشوض الهميش}

يتتاول البحث الصادرات الكلية والواردات الكلية المصرية خلال السلسلة الزمنية من سنة

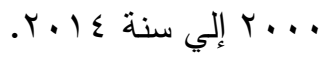

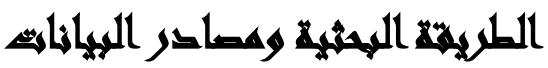

اعتمد البحث على كل من الأسلوب الوصفي حيث اعتمد البحث على البيانات الثانوية من

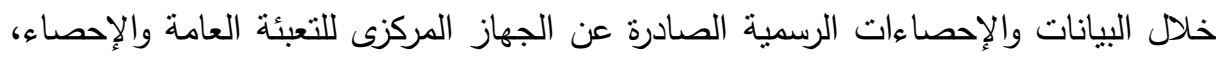
وزارة التخطيط، وتقارير البنك المركزي، وموقع البنك الدولي، وموقع منظمة الفاو في الفترة

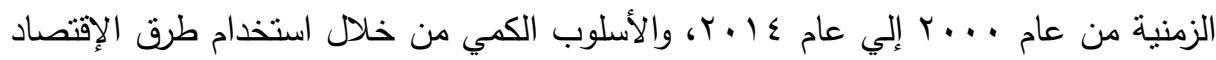
القياسي بإستخدام نماذج قياسية (التحليل الكمى) منل أسلوب الإنحدار البسيط والمتعدد في ماني

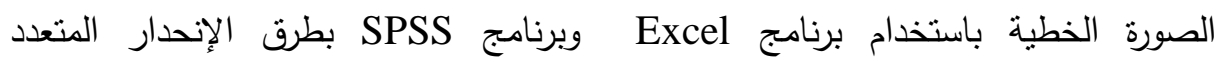
ومعادلات الاتجاه الزمنى العام في الفترة الزمنية (Backward, Stepwise , Forward)

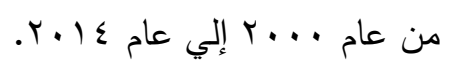

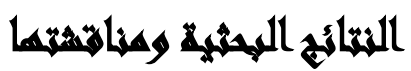

تطور التبادل التجاري بين مصر ومجموعات دول العالم:

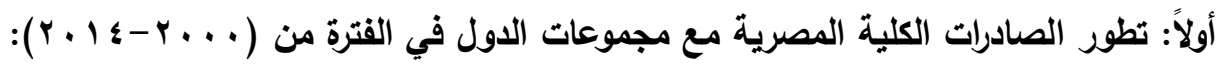
تشير نتائج جدول (1) إلي نتائج معادلات الاتجاه الزمني العام لنطور صادرات مصر الكلية

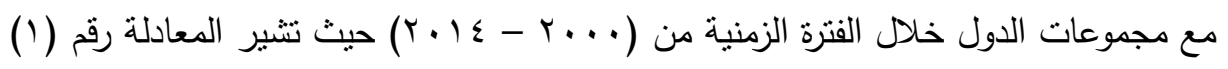

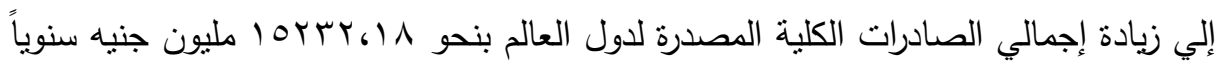
بمعدل تغير سنوي 7،؛؛ (\%، وقد ثثتت المعنوية الإحصائية لهذه الزيادة، ومعامل تحديد بلغ نحو 97\% مما يعني أن 97\% من التغير في قيمة الصادرات الكلية يرجع إلي عدة عوامل يعكسها عامل الزمن، وتثير قيم (F) إلى أن النموذج المستخدم في إجمالي صادرات مصر 
الكلية المصدرة لدول العالم معنوي عند مستوى معنوية (1 . , ·) وملائم لطبيعة البيانات. في حين حققت أكبر قيمة صادرات مصر الكلية إلي مجموعة دول غرب أوربا حيث

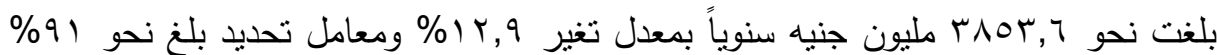
مما يعني أن • 9\% من التغير في قيمة الصادرات الكلية يرجع إلي عدة عوامل يعكسها عامل الزمن، وتتير قيم (F) إلى أن النموذج المستخدم في إجمالي صادرات مصر الكلية إلي مجموعة دول غرب أوربا معنوي عند مستوى معنوية (1 +. •) وملائم لطبيعة البيانات. جدول(1): تطور الإتجاه العام للصادرات الكلية المصرية مع مجموعات الدول في الفترة من معائ بالمليون جنيه

\begin{tabular}{|c|c|c|c|c|}
\hline ميدة (F) & 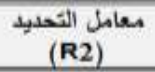 & Sien & الصعالة & الدول \\
\hline $357.98 *$ & 0.97 & 14.6 & $\begin{array}{c}Y=-17668.69+15232.18 x \\
(-2.41)^{* * *}(18.92)^{* *}\end{array}$ & الجملة \\
\hline $162.76^{\text {* }}$ & 0.93 & 18.5 & $\begin{array}{c}\gamma=-13932.80+5367.95 x \\
(-3.64)^{* * *}(12.76)^{* *}\end{array}$ & الثول العربية \\
\hline $129.60^{4 *}$ & 0.91 & 18.8 & $\begin{array}{c}Y=-4130.49+1612.53 x \\
(-3.35)^{* *}(11.38)^{* *}\end{array}$ & تُلقد أونا \\
\hline $123.95 * 0$ & 0.91 & 12.9 & $\begin{aligned} Y= & -1041.73+3853.60 x \\
& (-0.33)(11.13)^{* *}\end{aligned}$ & عزب أنسا \\
\hline $121.06 *$ & 0.91 & 13.8 & $\begin{array}{c}Y=-1645.64+2249.22 x \\
(-0.89)(11.03)^{* *}\end{array}$ & آسيا \\
\hline $50.8 *$ & 0.80 & 19.9 & $\begin{array}{c}Y=-2474.92+831.21 x \\
(-2.32)^{*} "(7.09)^{*}\end{array}$ & أنمريقيا \\
\hline $461.76^{\text {a }}$ & 0.97 & 12.9 & $\begin{array}{c}\gamma=-236.78+942.86 x \\
(-0.59)(21.49)^{4}\end{array}$ & أمريكا لمثمالية \\
\hline $26.51^{4 *}$ & 0.67 & 14.8 & $\begin{array}{c}\gamma=-15.28+12.47 x \\
(-0.69)(5.15)^{\circ}\end{array}$ & أمريكا الوسطفى \\
\hline $30.53^{\circ}$ & 0.70 & 19.7 & $\begin{array}{c}\gamma=-508.25+173.64 x \\
(-1.78)(5.53)^{* 0}\end{array}$ & أ \\
\hline $21.75 *$ & 0.63 & 16.6 & $\begin{array}{c}Y=-38.08+19.12 x \\
(-1.02)(4.66)=*\end{array}$ & الإثوانوسية \\
\hline 0.37 & 0.03 & 2.1 & $\begin{array}{c}Y=6535.45+169.56 x \\
(2.58)^{* *} *(0.61)\end{array}$ & يقرية الثول \\
\hline
\end{tabular}

المصدر: جمعت وحُسبت من بيانات جدول رقم (1) بالملحق.

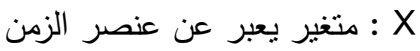
Y ب الصادرات المصرية الكلية القيم التي بين القوسين هي قيم ( T ) المحسوبة

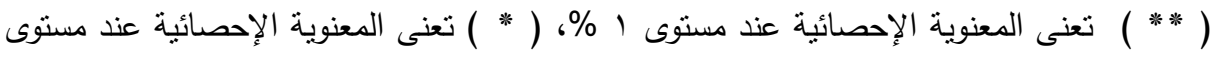
$\% \cdot, .0$ 
وحيث حققت أقل قيمة لصادرات مصر الكلية إلي مجموعة دول أمريكا الوسطي حيث

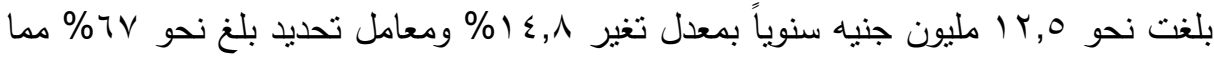

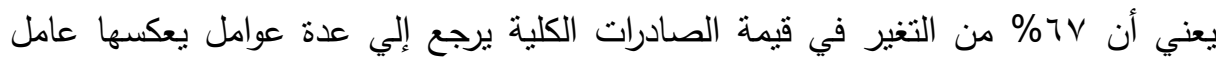

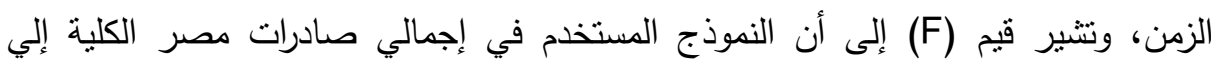
مجموعة دول أمريكا الوسطي معنوي عند مستوى معنوية (1 (., •) وملائم لطبيعة البيانات.

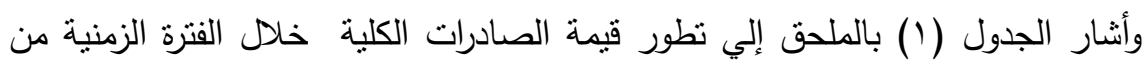

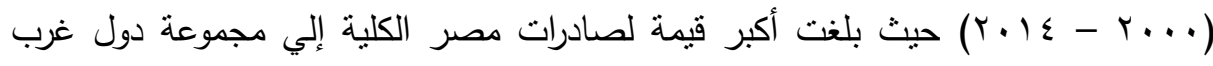

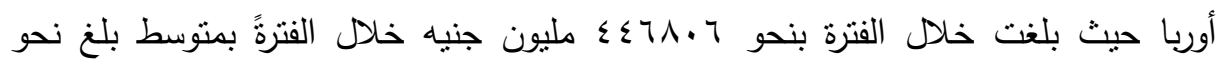
مليون جنيها، وبلغت أصغر قيمة صادرات مصر الكلية إلي مجموعة دول أمريكا

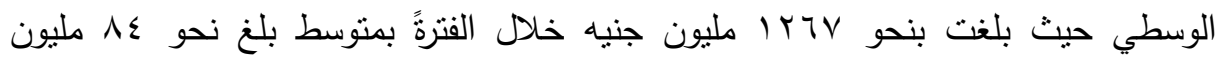
جنيها. تطور معامل عدم الاستقرار لقيمة صادرات مصر الكلية مع مجموعات الدول خلال الفترة

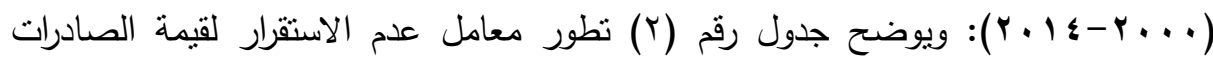

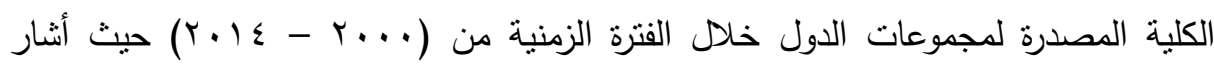

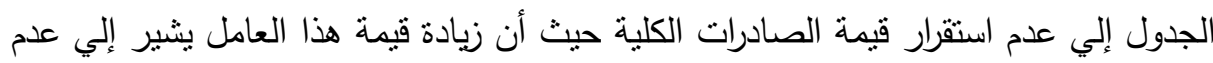
استقرار الصادرات الكلية وكلما اقتربت من الصفر دل ذللك علي استقرار قيمة الصادرات.

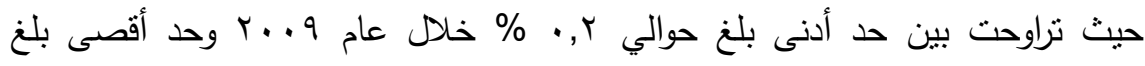

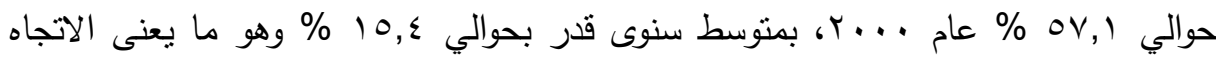
نحو انخفاض معامل عدم الاستقرار في قيمة الصادرات الكلية المصدرة لدول العالم خلال

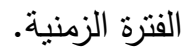
كما تبين من دراسة قيم معامل عدم الاستقرار لقيمة أكبر صادرات مصر الكلية إلي

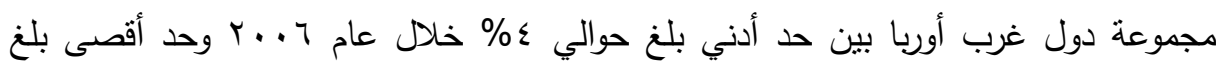

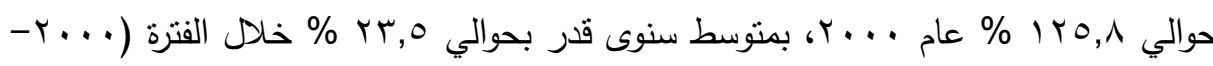

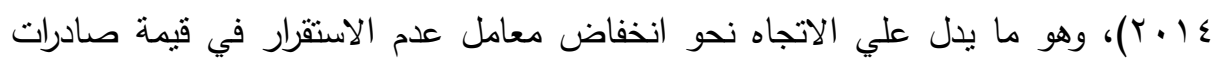


مصر الكلية إلي مجموعة دول غرب أوربا خلال الفترة الزمنية. جدول(ץ): معامل عدم الاستقرار لقيمة صادرات مصر الكلية مع مجموعات الدول في الفترة

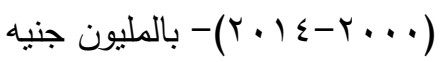

\begin{tabular}{|c|c|c|c|c|c|c|c|c|c|c|c|}
\hline مصادر & الافياتوسية & ألجنوبية & ألوسطى & أثماليكة & أفريق & آسيا & غرب أوربا & شرب & العربية & الجملة & السنوات \\
\hline 53.8 & 47.3 & 60.6 & 77.8 & 50.8 & 89.6 & 368.0 & 125.8 & 71.8 & 75.6 & 57.1 & r... \\
\hline 42.9 & 43.9 & 16.1 & 17.1 & 17 & 63.9 & 5.8 & 22.5 & 12.2 & 22.4 & 28.9 & $r \ldots r$ \\
\hline 42.9 & 1.4 & 484.2 & 81.9 & 44.6 & 76.6 & 12.9 & 44.5 & 48.6 & 63.6 & 24.6 & $r \ldots r$ \\
\hline 21.2 & 27.1 & 41 & 61.9 & 11.4 & 14.7 & 16 & 16.7 & 4.8 & 17.7 & 14.9 & $r \ldots r$ \\
\hline 3.2 & 89.5 & 68.3 & 116.7 & 12.7 & 40.9 & 28.1 & 12.9 & 15.5 & 32.8 & 18.5 & $r \ldots \varepsilon$ \\
\hline 51.2 & 67.4 & 69.5 & 78.2 & 5.2 & 51 & 34.1 & 10.6 & 30 & 36.4 & 16.4 & r...o \\
\hline 86.2 & 63.4 & 63.1 & 51.4 & 9.7 & 75.2 & 10.9 & 4 & 43.6 & 46.2 & 11.3 & $r \ldots r$ \\
\hline 158.2 & 41.7 & 81.2 & 52.6 & 13.7 & 65.9 & 12 & 14.5 & 43.3 & 51.8 & 12.4 & $r \ldots v$ \\
\hline 8.6 & 1.5 & 36.6 & 19.5 & 5.4 & 7.4 & 36.1 & 40.3 & 8.4 & 6.2 & 19.8 & $r \ldots \lambda$ \\
\hline 8.5 & 18.4 & 61.5 & 82.8 & 5.0 & 34 & 6.4 & 4.7 & 26.2 & 14.2 & 0.2 & r...q \\
\hline 28.9 & 19.9 & 48.4 & 2.4 & 4.4 & 16.6 & 1.7 & 8.1 & 14.7 & 8.9 & 3.3 & $r \cdot 1$. \\
\hline 22.1 & 99.1 & 44.1 & 30.3 & 2.5 & 6.1 & 15.1 & 20.4 & 13.9 & 7.9 & 14.1 & $r .11$ \\
\hline 13.6 & 31.1 & 5.9 & 15.5 & 9.4 & 12.3 & 7.7 & 8.7 & 0.8 & 2.2 & 1 & r.Ir \\
\hline 27.5 & 17.7 & 28.7 & 20.9 & 7.8 & 18 & 5.5 & 6.8 & 18.4 & 5.4 & 1.1 & $r .1 r$ \\
\hline 32.5 & 28.4 & 30 & 6 & 7.3 & 14 & 21.3 & 12.4 & 7.4 & 3.9 & 7.4 & $r . l \varepsilon$ \\
\hline 40.1 & 39.9 & 75.9 & 47.7 & 13.8 & 39.1 & 38.8 & 23.5 & 24.0 & 26.3 & 15.4 & المتوسط \\
\hline
\end{tabular}

حيث أن قيم معامل عدم الاستقرار الاستقرار لقيمة الصادرات الكلية المصدرة لدول العالم وبدراسة الاستقرار النسبي لقيمة أصغر صادرت مصر الي مجموعة دول الاسنرار لمرئه أمريكا الوسطي

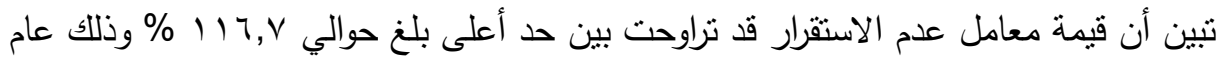

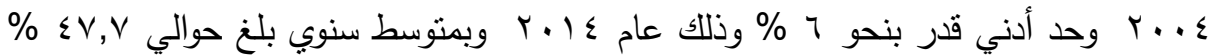


مما يدل على الاتجاه نحو انخفاض معامل عدم الاستقرار في صادرت مصر الي مجموعة دول أمريكا الوسطي خلال الفترة الزمنية.

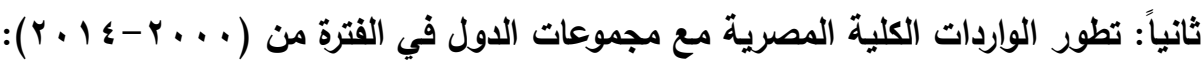

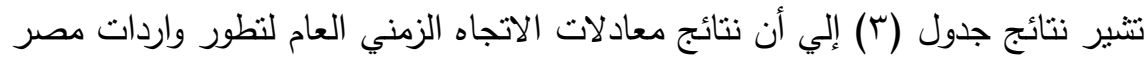

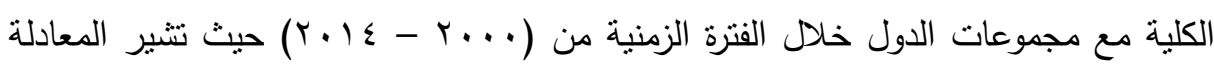

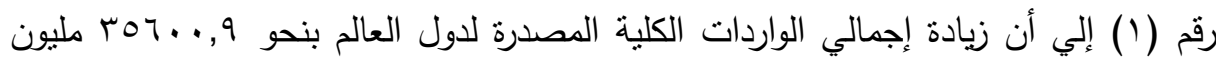

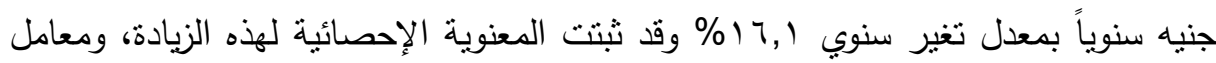

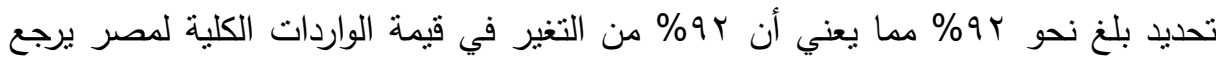

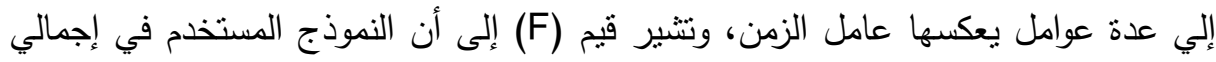

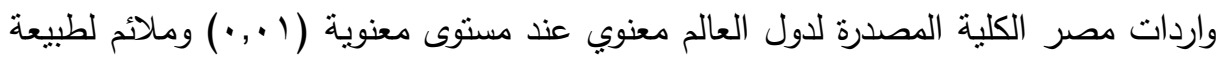
البيانات.

في حين حققت أكبر قيمة لواردات مصر الكلية من مجموعة دول غرب أوربا حيث

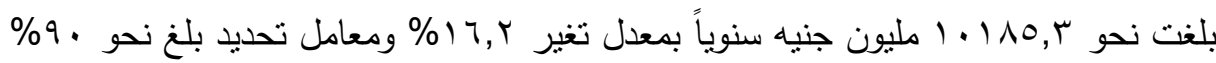

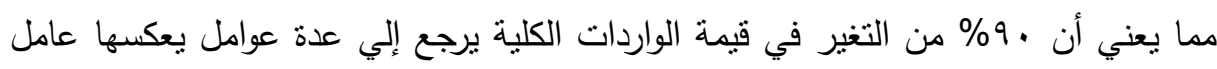

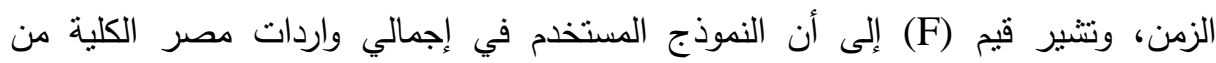
مجموعة دول غرب أوربا معنوي عند مستوى معنوية (1 (., •) وملائم لطبيعة البيانات. وحيث حققت أصغر قيمة لواردات مصر الكلية من مجموعة دول أمريكا الوسطي حيث ديثل

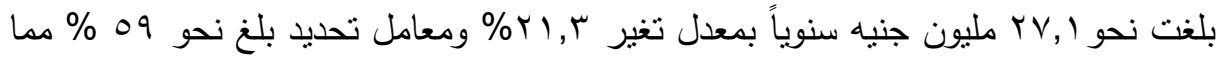

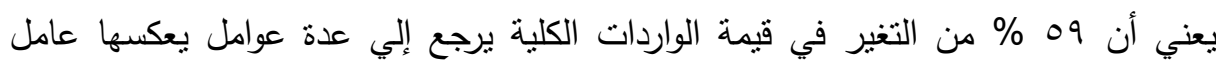
الزمن، وتتثير قيم (F) إلى أن النموذج المستخدم في إجمالي واردات مصر الكلية إلي لئي مجموعة دول أمريكا الوسطي معنوي عند مسنوى معنوية (1 (., •) وملائم لطبيعة البيانات.

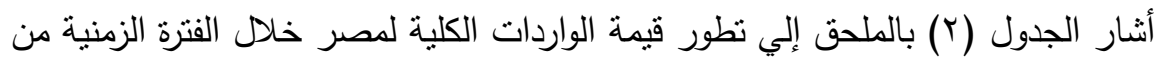

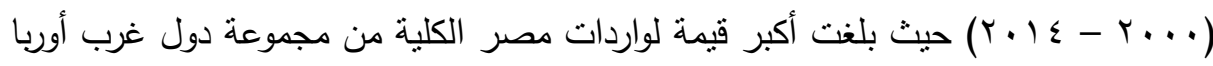

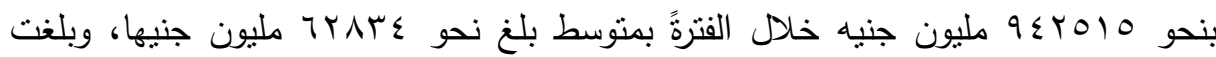


أصغر قيمة لواردات مصر الكلية من مجموعة دول أمريكا الوسطي حيث بلغت بنحو 19.0

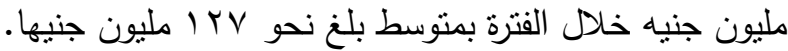
جدول(r): تطور الإتجاه العام للواردات الكلية المصرية مع مجموعات الدول في الفترة من

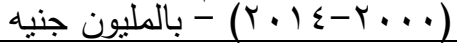

\begin{tabular}{|c|c|c|c|c|}
\hline قيمة ف (F) & معامل التصديد (R2) & التغير & المعادلة & المتغيرات \\
\hline $166.08 \% *$ & 0.93 & 16.1 & $\begin{aligned} Y= & -64215.74+35600.87 x \\
& (-2.56)^{* * *}(12.89)^{* * *}\end{aligned}$ & الجملة \\
\hline $166.83^{* *}$ & 0.93 & 16.6 & $\begin{array}{c}Y=-9643.82+4867.61 x \\
(-2.82)^{* * *}(12.92)^{* * *}\end{array}$ & 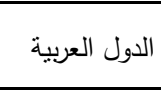 \\
\hline $94.91 \%$ & 0.88 & 18.8 & $\begin{aligned} Y= & -16898.21+6286.89 x \\
& (-2.88)^{* * *}(9.74)^{* * * *}\end{aligned}$ & شرق أوربا \\
\hline $116.57 \%$ & 0.90 & 16.2 & $\begin{array}{c}\mathrm{Y}=-18648.32+10185.33 \mathrm{x} \\
(-2.18)^{*}(10.81)^{* * *}\end{array}$ & غرب أوربا \\
\hline $112.43 \%$ * & 0.90 & 18.5 & $\begin{aligned} Y= & -23718.39+9103.43 x \\
& (-3.04)^{* * *}(10.60)^{* * *}\end{aligned}$ & آسيا \\
\hline $38.68 * *$ & 0.75 & 15.4 & $\begin{array}{c}Y=-624.03+417.50 x \\
(-1.02)(6.22)^{* * *}\end{array}$ & أفريقيا \\
\hline $77.61 \% *$ & 0.86 & 13.3 & $\begin{aligned} \mathrm{Y}= & -1476.04+2919.19 \mathrm{x} \\
& (-0.49)(8.81)^{* * *}\end{aligned}$ & أمريكا الثمالية \\
\hline $18.85^{* *}$ & 0.59 & 21.3 & $\begin{array}{c}Y=-90.09+27.14 x \\
(-1.59)(4.34)^{* * *}\end{array}$ & أمريكا الوسطى \\
\hline $93.16 \%$ & 0.88 & 17.2 & $\begin{aligned} Y= & -4587.93+2113.90 x \\
& (-2.30)^{*}(9.65)^{* * *}\end{aligned}$ & أمريكا الجنوبية \\
\hline $32.99 \%$ & 0.72 & 8 & $\begin{array}{c}Y=920.36+262.49 x \\
(2.22)^{*}(5.75)^{* * *}\end{array}$ & الاقيانوسية \\
\hline 1.89 & 0.13 & $10^{-}$ & $\begin{aligned} \mathrm{Y}= & 10548.69-584.56 \mathrm{x} \\
& (2.74)^{* *}(-1.38)\end{aligned}$ & مصادر أخرى \\
\hline
\end{tabular}

المصدر : جمعت وحُسبت من بيانات جدول رقم (Y) بالملحق.

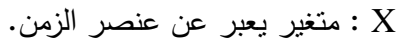

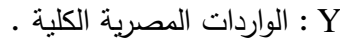
القيم التي بين القوسين هي قيم ( T ) المحسوبة القية

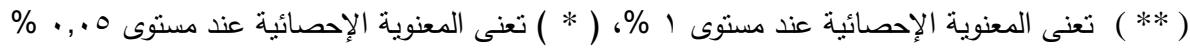

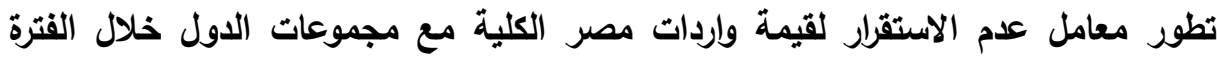

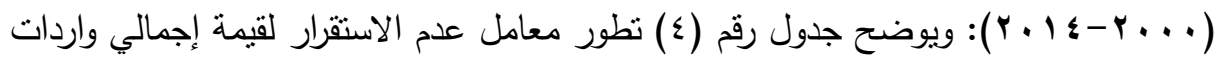

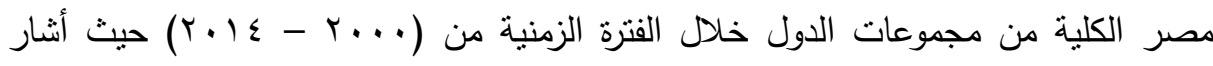


الجدول إلي عدم استقرار قيمة الواردات الكلية حيث أن زيادة قيمة هذا العامل يشير إلي عدم استقرار إجمالي واردات مصر الكلية وكلما اقتربت من الصفر دل ذلك علي استقرار قيمة

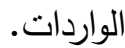
جدول(؛): معامل عدم الاستقرار لقيمة واردات مصر الكلية من مجموعات الدول في الفترة

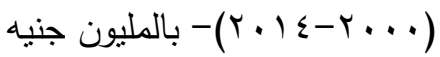

\begin{tabular}{|c|c|c|c|c|c|c|c|c|c|c|c|}
\hline أخرى & الافيانوسية & أمريكا & ألوسطى & أشمريكا & أفريقيا & آسيا & غروبا & شرق أوربا & العربية & الجملة & السنوات \\
\hline 78.4 & 53.2 & 40 & 85.7 & 42.8 & 153.7 & 46.6 & 107.8 & 56.6 & 6 & 70 & r... \\
\hline 63.2 & 63.2 & 48.5 & 83.3 & 79.2 & 178.2 & 50.6 & 85.3 & 15.5 & 478.7 & 62.5 & $r \ldots$ \\
\hline 36.7 & 47.0 & 78.4 & 48.1 & 9.4 & 87.6 & 161.7 & 38.5 & 217.7 & 17.8 & 32.6 & $r \ldots r$ \\
\hline 12.0 & 20 & 11.1 & 160.0 & 22.3 & 5.5 & 22.3 & 17.8 & 11.1 & 42.3 & 16.8 & $r . . r$ \\
\hline 22.3 & 15 & 18.4 & 53.8 & 32.5 & 53.5 & 37.4 & 32.3 & 38.6 & 38.2 & 29.9 & $r \ldots \varepsilon$ \\
\hline 106.8 & 2.8 & 17.6 & 6.3 & 31.5 & 50.5 & 43.1 & 36.7 & 21.9 & 5.7 & 23.2 & r... \\
\hline 165.5 & 26.9 & 44.7 & 96.0 & 47.6 & 75.4 & 49.2 & 48.7 & 51.2 & 7.1 & 36 & $r . . r$ \\
\hline 295.9 & 40.2 & 37.3 & 96.1 & 29.3 & 65.1 & 52.7 & 44.9 & 45.1 & 6.8 & 30.8 & $r \ldots v$ \\
\hline 78.1 & 22.2 & 2 & 91.6 & 38.5 & 67.2 & 13.1 & 17.7 & 5.1 & 18.3 & 12.3 & $r \ldots \lambda$ \\
\hline 93.3 & 24.9 & 38.4 & 73.0 & 5.5 & 6.5 & 13.3 & 4.1 & 18.2 & 28.1 & 14.3 & $r \ldots q$ \\
\hline 90.1 & 8.8 & 17.1 & 37.0 & 1.6 & 5.5 & 1.4 & 1.5 & 19.1 & 19.2 & 8.3 & r.l. \\
\hline 81 & 14.6 & 25.8 & 47.6 & 26.4 & 26.6 & 1.4 & 0.3 & 5.1 & 1.5 & 2.3 & r. 11 \\
\hline 99.5 & 19.1 & 14.6 & 81.9 & 2.9 & 22.3 & 5 & 5.9 & 29.3 & 6.7 & 8.8 & $r .1 r$ \\
\hline 69.3 & 16.6 & 15.4 & 29.2 & 2.2 & 9.1 & 5.1 & 8.3 & 4.6 & 2.9 & 5 & $r .1 r$ \\
\hline 92.9 & 27.5 & 0.6 & 10.9 & 4.3 & 9.7 & 18.9 & 9.7 & 16 & 15.5 & 11.4 & $r \cdot 1 \leqslant$ \\
\hline 92.3 & 26.8 & 27.3 & 66.7 & 25.1 & 54.4 & 34.8 & 30.6 & 37.0 & 46.3 & 24.3 & المتوسط \\
\hline
\end{tabular}

المصدر : جُمعت وحُسبت من جدول رقم (Y) بالملحق بالقانون $\mathrm{Y}^{\wedge}$

حيث أن قيم معامل عدم الاستقرار لقيمة إجمالي واردات مصر الكلية من دول العالم

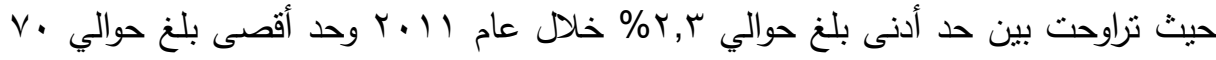

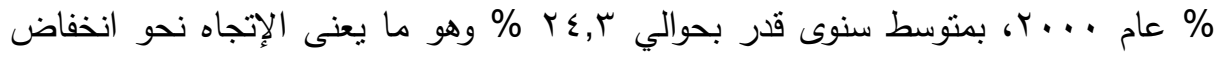

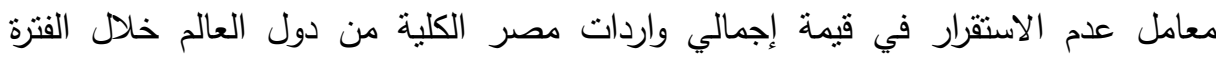
406 
كما تبين من دراسة قيم معامل عدم الاستقرار لأكبر قيمة لواردات مصر الكلية من

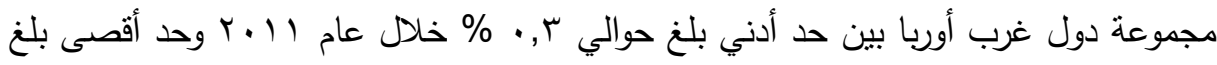

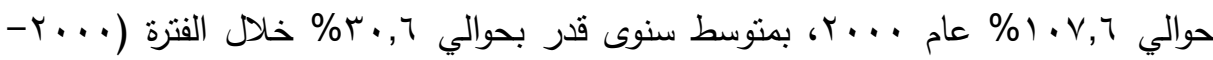

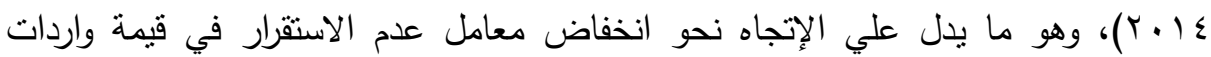
مصر الكلية من مجموعة دول غرب أوربا.

وبدراسة الاستقرار النسبي لأصغر قيمة لواردات مصر الكلية من مجموعة دول أمريكا

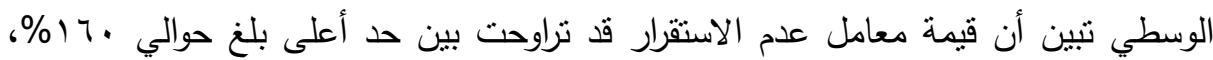

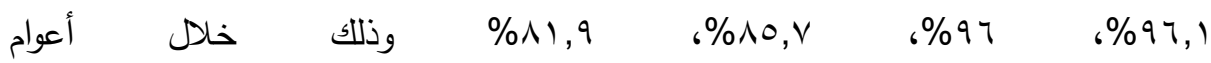

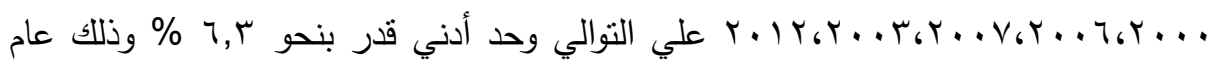

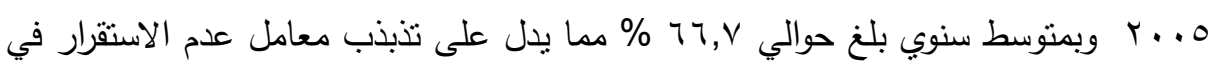
لواردات مصر الكلية من مجموعة دول أمريكا الوسطي خلال الفترة الزمنية.

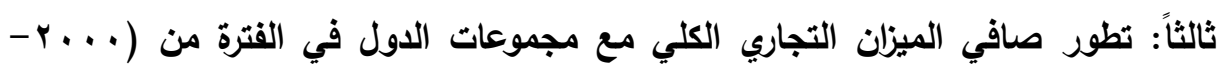

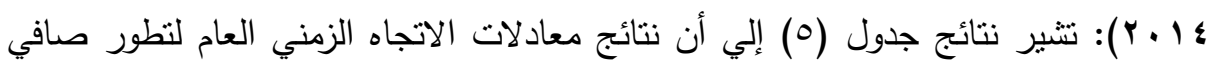

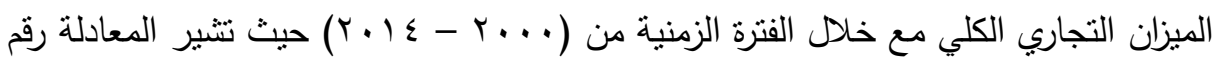

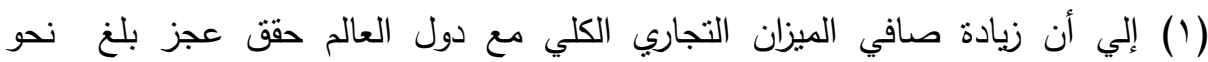

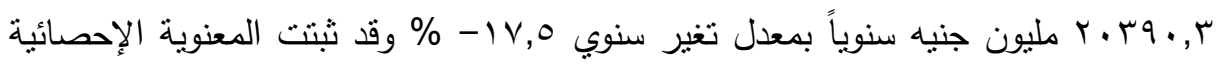

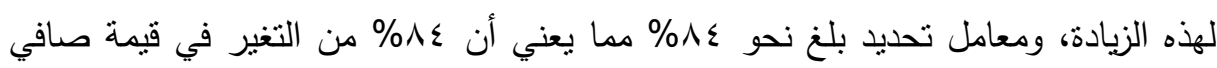

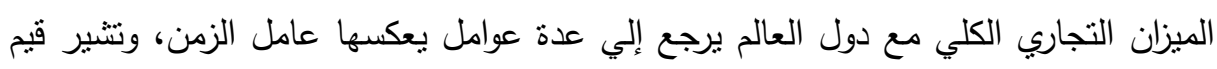

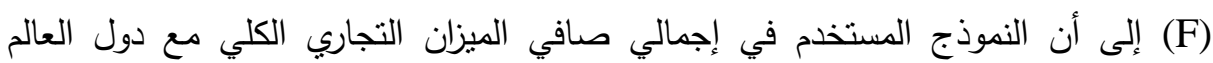
معنوي عند مستوى معنوية (1 +., · ) وملائم لطبيعة البيانات.

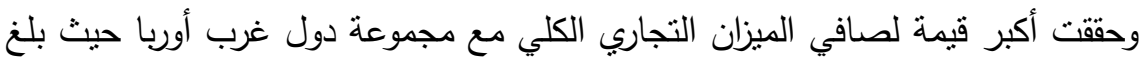

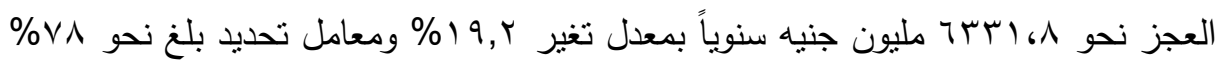

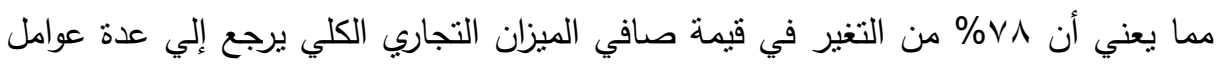
يعكسها عامل الزمن، وتتشير قيم (F) إلى أن النموذج المستخدم في صافي الميزان التجاري 
الكلي إلي مجموعة دول غرب أوربا معنوي عند مستوى معنوية (1.,.) وملائم لطبيعة

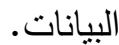
جدول(ه): نطور الإتجاه العام لصافي الميزان التجاري الكلي مع مجموعات الدول في الفترة

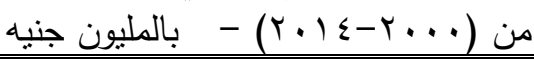

\begin{tabular}{|c|c|c|c|c|}
\hline قيمة ف (F) & $\begin{array}{c}\text { معامل التحديد } \\
\left(\mathbf{R}^{2}\right)\end{array}$ & معدل التغير & المعادلة & المتغيرات \\
\hline$T V, 00 \% *$ & $\cdot, \wedge \varepsilon$ & IV,o- & $\begin{array}{c}Y=46651.81-20390.27 x \\
(2.07)^{*}(-8.22)^{* * *}\end{array}$ & الجملة \\
\hline $1, \cdot v$ & $\cdot, \cdot \wedge$ & $\mid V, \wedge-$ & $\begin{array}{c}Y=-4289.21+500.37 x \\
(-0.98)(1.04)\end{array}$ & الدول العربية \\
\hline$V \Gamma, Y \Psi * *$ & $\cdot, 10$ & $\curlywedge \wedge, \wedge-$ & $\begin{aligned} \mathrm{Y}= & 12587.45-4674.34 \mathrm{x} \\
& (2.54)^{* * *}(-8.56)^{* * *}\end{aligned}$ & شرق أوربا \\
\hline$\leq 0, \Upsilon ৭ * *$ & $\cdot, \vee \wedge$ & $19, Y-$ & $\begin{array}{c}\mathrm{Y}=17607.04-6331.77 \mathrm{x} \\
(2.06)^{*}(-6.73)^{* * *}\end{array}$ & غرب أوربا \\
\hline$\pi r, \ldots * *$ & • & $r \cdot, q-$ & $\begin{aligned} Y= & 22072.75-6854.21 x \\
& (2.79) * *(-7.87)^{* * *}\end{aligned}$ & آسيا \\
\hline Y $\vee, Y q * *$ & $\cdot, \uparrow \wedge$ & $\lceil\wedge, \varepsilon$ & $\begin{array}{c}Y=-1851.11+413.72 x \\
(-2.57)^{* * *}(5.22)^{* * \frac{*}{*}}\end{array}$ & أفريقيا \\
\hline rV,乏.** * & $\cdot, \mathrm{V} \varepsilon$ & $1 r, 7-$ & $\begin{aligned} \mathrm{Y}= & 1239.54-1976.36 \mathrm{x} \\
& (0.42)(-6.12)^{* * *}\end{aligned}$ & أمريكا الشمالية \\
\hline$\curlyvee, \wedge \curlyvee * *$ & • ro & $r \leqslant, 0-$ & $\begin{array}{c}\mathrm{Y}=74.81-14.67 \mathrm{x} \\
(1.47)(-2.62)^{* \%}\end{array}$ & أمريكا الوسطى \\
\hline $90, \wedge$ 世苂 & $\cdot, \wedge \wedge$ & IV,.- & $\begin{aligned} \mathrm{Y}= & 4080.34-1940.39 \mathrm{x} \\
& (2.26)^{*}(-9.79)^{* \text { ** }}\end{aligned}$ & أمريكا الجنوبية \\
\hline 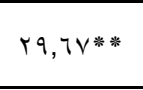 & $\cdot, 79$ & $\wedge, \varepsilon-$ & $\begin{array}{c}Y=-958.17-243.40 x \\
(-2.36)^{*}(-5.45)^{* * *}\end{array}$ & الاقيانوسية \\
\hline $17, \leqslant V^{* * *}$ & $\cdot, 00$ & $r v, r$ & $\begin{aligned} Y= & -4013.24+754.12 x \\
& (-2.38)^{*}(4.06)^{* * *}\end{aligned}$ & مصادر أخرى \\
\hline
\end{tabular}

المصدر: جمعت وحُسبت من بيانات جدول رقم(1)،(Y) بالملحق. | متغير يعبر عن عنصر الزمن. X Y القيم التي بين القوسين هي قيم ( T ) المحسوبة ( *** ) تعنى المعنوية الإحصائية عند مسنوى ا \%٪، ( * ) تعنى المعنوية الإحصائية عند مستوى 
وحيث حققت أصغر قيمة لصافي الميزان التجاري الكلي إلي مجموعة دول أمريكا

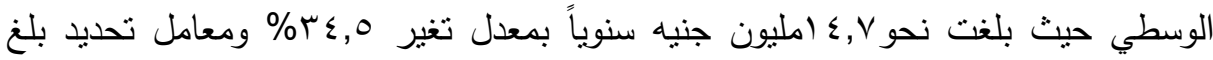

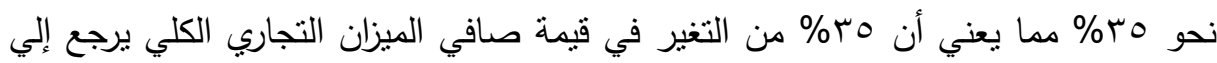

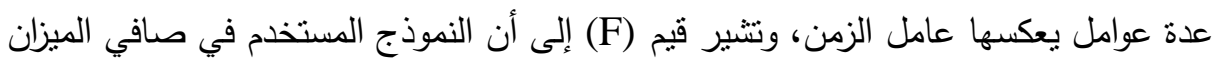

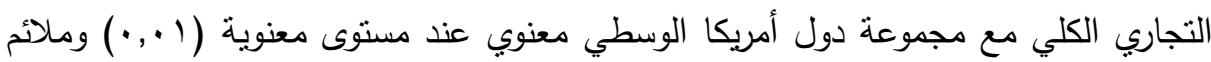
لطبيعة البيانات.

أثنار الجدول (1)، (Y) بالملدق إلي تطور قيمة صافي الميزان التجاري الكلي خلال

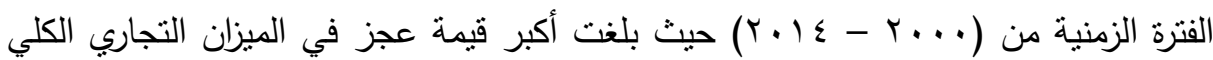

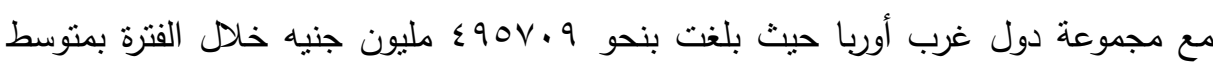

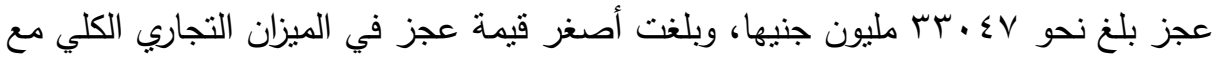

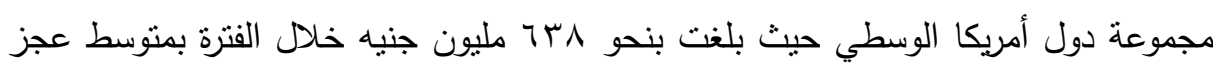
بلغ نحو ع مليون جنيها. تطور معامل عدم الاستقرار لقيمة صافي الميزان التجاري الكلي مع مجموعات الدول

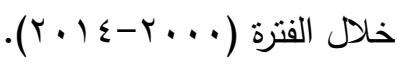

ويوضح جدول رقم (†) تطور معامل عدم الاستقرار لقيمة صافي الميزان التجاري الكلي

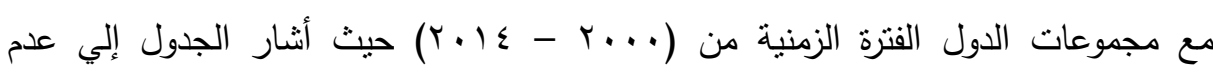

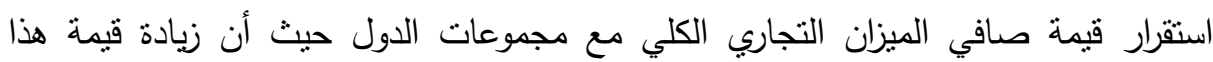

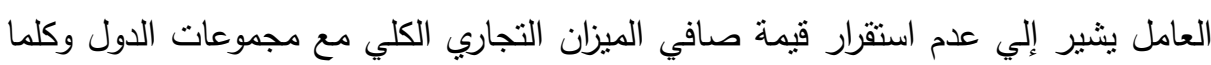
اقتربت من الصفر دل ذلك علي استقرار قيمة صافي الميزان التجاري.

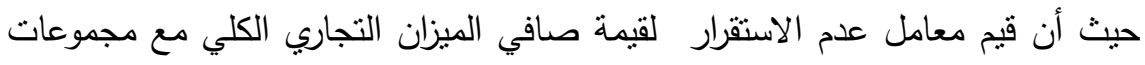

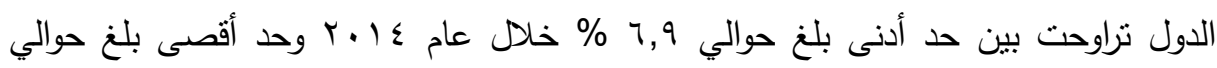

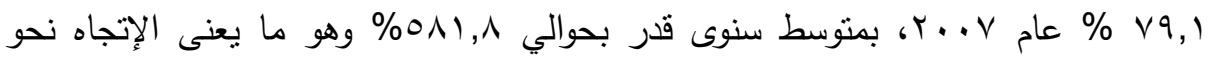

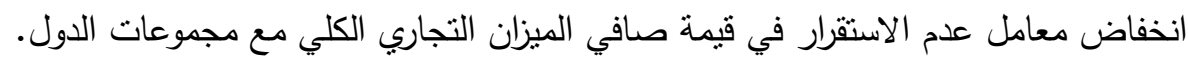


كما تبين من دراسة قيم معامل عدم الاستقرار لأكبر قيمة عجز في صافي الميزان

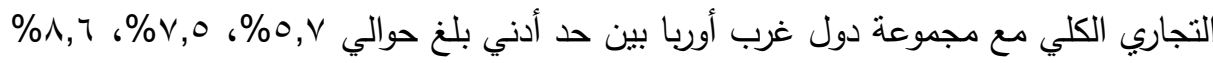

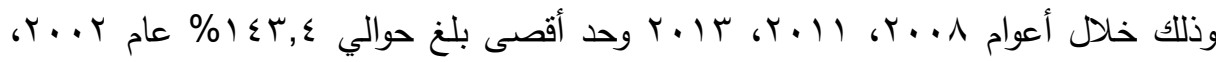

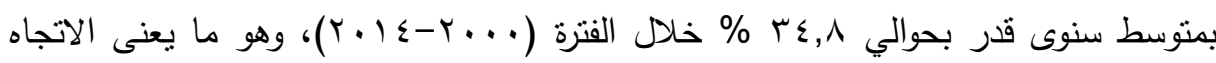
نحو انخفاض معامل عدم الاستقرار في صافي الميزان التجاري الكلي مع مجموعة دول غرب

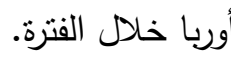
جلول(؟): معامل عدم الاستقرار لقيمة صافي الميزان التجاري الكلي مع مجموعات الدول

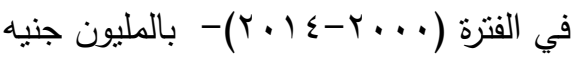

\begin{tabular}{|c|c|c|c|c|c|c|c|c|c|c|c|}
\hline نَّهن & ensig & لجيريك & 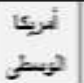 & فرئرية & ألتزيكا & i & 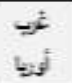 & لريطا & ل2 & جمبكا" & in \\
\hline 85.5 & 47.5 & 36.8 & 93.3 & 74.1 & 124.6 & 67.3 & 0.3 & 50.7 & 178.5 & 23 & $T+\ldots$ \\
\hline 111.3 & 58.3 & 88.8 & 95.6 & 136.1 & 149.3 & 36.9 & 127.6 & 29.7 & 160.4 & 48.2 & $r \ldots 1$ \\
\hline 188.2 & 42.3 & 75.5 & 70.8 & 31.7 & 236.2 & 228.1 & 66.8 & 261.1 & 118.8 & 143.4 & 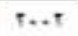 \\
\hline 451.7 & 23.1 & 13.8 & 179 & 28.7 & 165.7 & 30.9 & 19.8 & 19.8 & 76.7 & 19 & $T \ldots T$ \\
\hline 80.4 & 7.8 & 15.2 & 5.4 & 43.5 & 43.9 & 44.7 & 57.5 & 48.1 & 122.9 & 42.1 & $T \cdots E$ \\
\hline 514.9 & 5.5 & 14 & 316.4 & 50.4 & 52.6 & 48.7 & 65.1 & 19.9 & 229.5 & 29.9 & r... \\
\hline 118.6 & 29.5 & 43.3 & 11.2 & 77.1 & 74.6 & 70 & 99.8 & 54.4 & 137.0 & 58.8 & T... \\
\hline 42.0 & 43.4 & 33.9 & 17.7 & 37.9 & 67.2 & 85 & 72.3 & 46.2 & 174.8 & 47.3 & T.. \\
\hline 173.8 & 27.6 & 0.7 & 13.6 & 54.9 & 92.6 & 2.3 & 1.7 & 4.5 & 171.6 & 5.7 & T..A \\
\hline 104.4 & 29.6 & 36.6 & 572 & 5.5 & 76.8 & 16.4 & 11.3 & 15.9 & 332.5 & 26.8 & $T+\ldots$ \\
\hline 29.9 & 3.6 & 22.4 & 113.9 & 0.1 & 32.9 & 1.2 & 9.1 & 21 & 302.4 & 18.1 & T+1. \\
\hline 19.2 & 3.3 & 24.3 & 269.9 & 38.2 & 109.5 & 8.3 & 15.2 & 12.1 & 273.5 & 7.5 & ++11 \\
\hline 30.2 & 10.9 & 15.3 & 404.6 & 9.4 & 1.4 & 3.9 & 16.9 & 38.7 & 17.8 & 16.8 & T.וT \\
\hline 12.4 & 10.9 & 14.3 & 160.5 & 0.3 & 16.2 & 4.9 & 19.6 & 0.6 & 58.0 & 8.6 & T.1T \\
\hline 17.7 & 22.2 & 3.1 & 168.9 & 3.1 & 19.5 & 34.9 & 25.9 & 18.6 & 24.5 & 26.6 & $1 \pm$ \\
\hline 132.0 & 24.4 & 29.2 & 166.2 & 39.4 & 84.2 & 45.6 & 40.6 & 42.8 & 158.6 & 34.8 & (1) \\
\hline
\end{tabular}

المصدر: جُمعت وحُسبت من جدول رقم ( ، Y ) بالملدق بالقانون ( 
وبدراسة الاستقرار النسبي لأصغر قيمة عجز في صافي الميزان التجاري الكلي مع

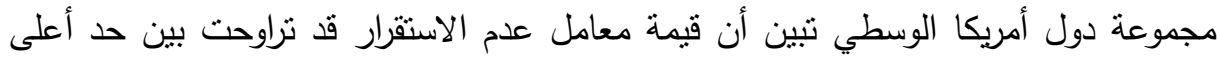

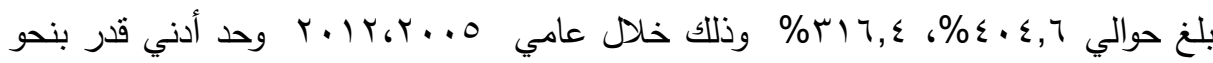

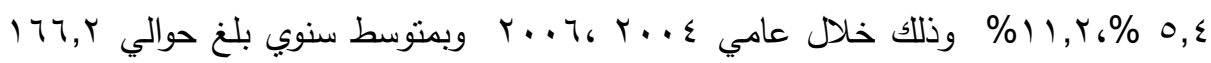
\% مما يدل على تذبذب معامل عدم الاستقرار في صافي الميزان التجاري الكلي مع مجموعة دول أمريكا الوسطي خلال الفترة. رابعاً: التقدير الإحصائي لبعض المتغيرات الإقتصادية وأتثرها علي التبادل التجاري المصري.

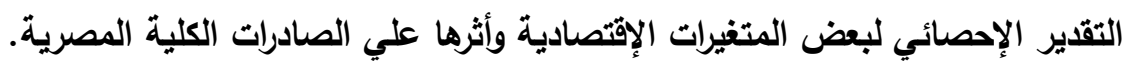

$$
\begin{aligned}
& \text { :د2 } \\
& \text { X4 الناتج المحلي الإجمالي لئي } \\
& \text { X6 } \\
& \text { X8 } \\
& \text { X10 :اتفاقية منطقة التجارة الحرة (تيسير ) } \\
& \text { X12 }
\end{aligned}
$$$$
\text { :اتفاقية الثراكة الاوربية X14 }
$$

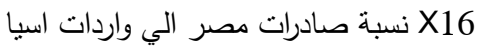$$
\text { X21 }
$$$$
\text { X29 : : عدد سكان الاتحاد الاوربي }
$$

الصادرات الكلية Y1

$$
\text { X1 }
$$$$
\text { X3 :عدد السكان X3 }
$$$$
\text { معد X5 }
$$

X9 :الاحتياطي من النقد الأجنبي X11: X9

X11 X13

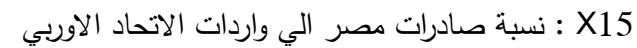
X20 : واردات الاتحاد الاوربي لي

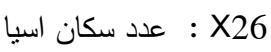

يشير جدول تطور اجمالي الصادرات الكلية رقم (V) وأهم المتغيرات الاقتصادية المؤثرة

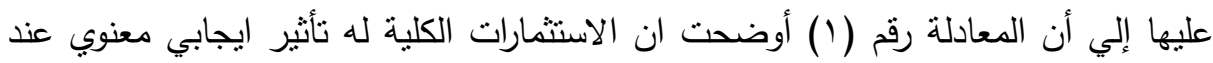

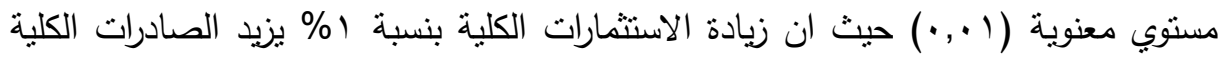

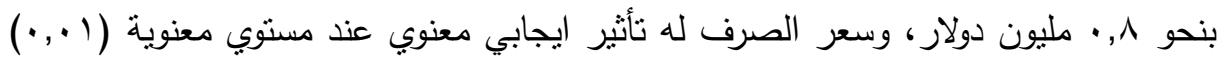

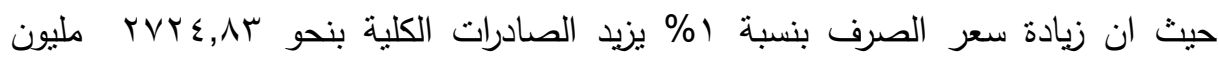

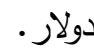

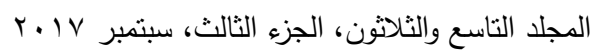


يشير جدول تطور اجمالي الصادرات الكلية رقم (V) وأهم المتغيرات الاقتصادية المؤثرة عليها إلي ان المعادلة رقم (Y) أوضحت ان الناتج المحلي الإجمالي له تأنثير ايجابي معنوي

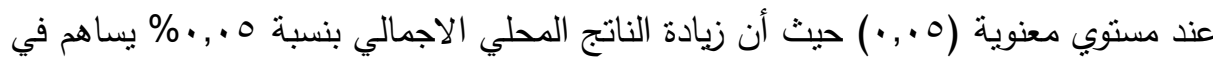

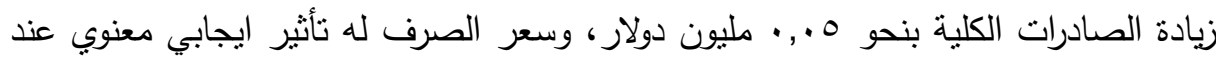

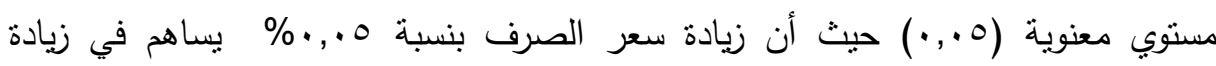

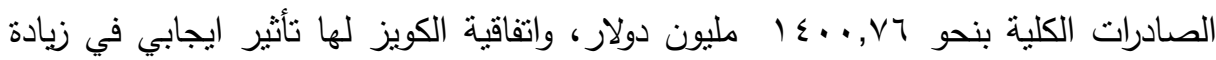
الصادرات الكلية عند مستوي معنوية (1.,.•) حيث أن زيادة الصادرات الكلية في اتفاقية

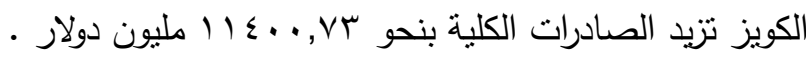

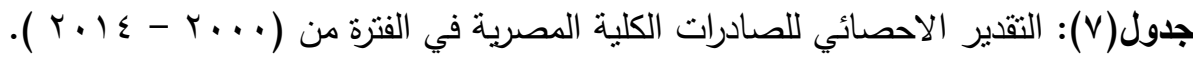

\begin{tabular}{|c|c|c|c|c|}
\hline $\mathbf{F}$ & $R \cdot 2$ & المعالة & نوع المعادلة & المعادلة \\
\hline $283.66^{*}=$ & 0.89 & 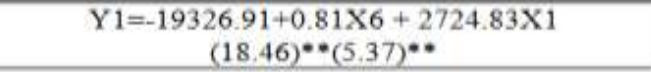 & stepwise & 1 \\
\hline $42.94=$ & 0.92 & $\begin{array}{c}\mathrm{Y} 1=.4094 .05+0.05 \times 4+1400.76 \mathrm{X} 1+ \\
11400.73 \times 13 \\
(2.13)^{*}(0.13)(3.54)^{* *}\end{array}$ & backward & r \\
\hline $82.73=4$ & 0.93 & $\begin{array}{c}\mathrm{Y} 1=-2331.12+13.67 \times 2+.07 \mathrm{X} 4 \\
(4.42)^{* *}(4.34)^{* *}\end{array}$ & stepwise & $r$ \\
\hline $1770.7^{=*}$ & 0.98 & $\begin{array}{c}\mathrm{Y} 1=15532.57+2216.75 \times 1+0.717 \times 6= \\
0.34 \times 7+4338.18 \times 10 \\
(4.16)^{* *}(11.23)^{* *}(-2.09)^{*}(2.03)^{*}\end{array}$ & backward & $\varepsilon$ \\
\hline $121.08=$ & 0.97 & $\begin{array}{c}\mathrm{Y} 1=-5148.75+0.57 \times 6+4436.08 \times 14+3446.49 \times 15 \\
(5.34)^{* *}(2.88)^{* *}(2.46)^{* *}\end{array}$ & forward & 0 \\
\hline $68.26^{*}=$ & 0.92 & $\begin{array}{c}\mathrm{Y} 1=994.13+6681.9 \times 15+12.99 \times 2 \\
(3.71)^{* *}(3.53)^{* *}\end{array}$ & fortvard & 7 \\
\hline $107.13^{\circ}$ & 0.98 & $\begin{array}{c}Y 1=-2546.41+0.06 \times 4+6853.18 \times 11+5040.80 \times 10 \\
(2.34)^{* *}(1.97)^{*}(2.39)^{* *}\end{array}$ & 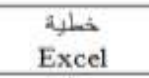 & $v$ \\
\hline $69.09 * 4$ & 0.92 & $\begin{array}{c}\mathrm{Y} 1=6566.79+18871.57 \times 11+0.49 \times 7 \\
(11.16)^{* *}(2.22)^{*}\end{array}$ & $\begin{array}{l}\text { aylat } \\
\text { Excel }\end{array}$ & $\wedge$ \\
\hline $58.01^{* *}$ & 0.96 & $\begin{array}{c}\mathrm{Y} 1=-3082519.63+-.079 \times 19+4.64 \times 20+10.49 \times 2+ \\
2928.03 \times 1 \\
(-2.75)^{* *}(3.75)^{* *}(2.95)^{* *}(2.29)^{*}\end{array}$ & backward & 4 \\
\hline $46.39 *$ & 0.89 & $\begin{array}{c}Y 1=133.79+4235.72 \times 16+8247.08 \times 10 \\
(4.52)^{* *}(2.71)^{* *}\end{array}$ & stepwise & 1, \\
\hline $75.99 *$ & $0.95 \cdot$ & $\begin{array}{c}\mathrm{Y} 1=137.53+0.28 \times 18+0.37 \times 17-3316.19 \times 1 \\
(2.53) * *(4.59) * *(-2.84)^{* *}\end{array}$ & backward & "1 \\
\hline
\end{tabular}

المصدر: جُمعت وحُسبت من جدول رقم (َ)،(؟) بالملحق 
يشير جدول نطور اجمالي الصادرات الكلية رقم (V) وأهم المتغيرات الاقتصادية المؤثرة

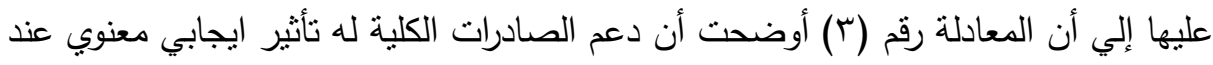

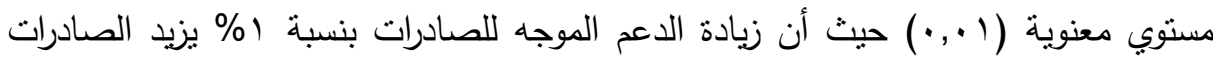

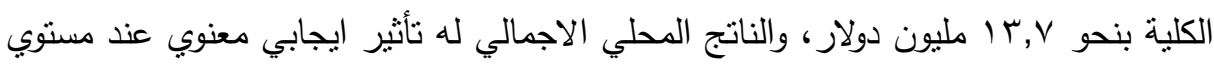

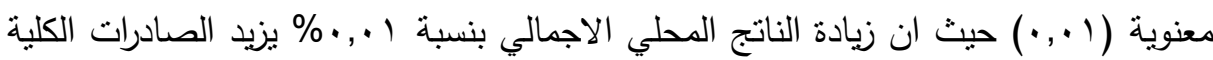
بنحو V, • مليون دولار يشير جدول نطور اجمالي الصادرات الكلية رقم (V) وأهم المتغيرات الاقتصادية المؤثرة عليها إلي ان المعادلة رقم (ع) أوضحت ان سعر الصرف لـ له نأثير ايجابي معنوي عند مستوي

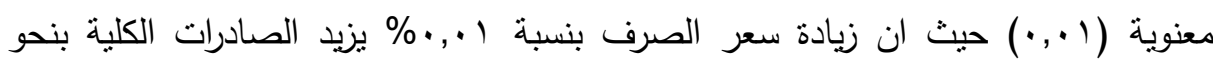

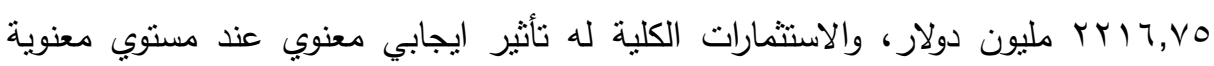

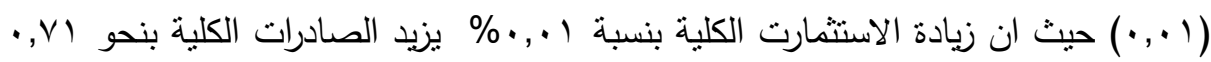

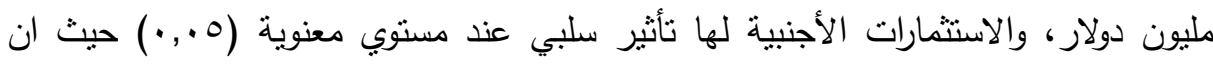

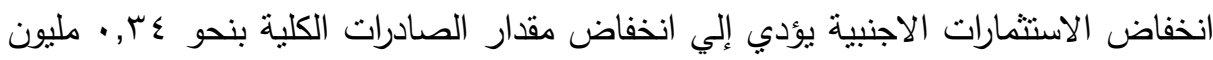

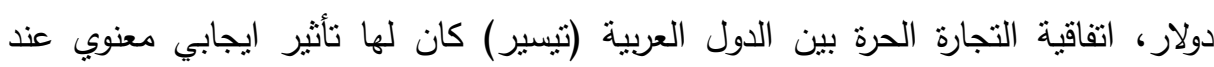

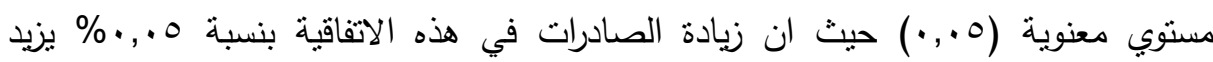

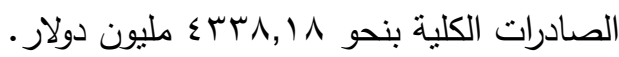
يشير جدول نطور اجمالي الصادرات الكلية رقم (V) وأهم المتغيرات الاقتصادية المؤثرة

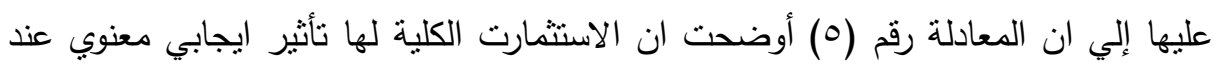

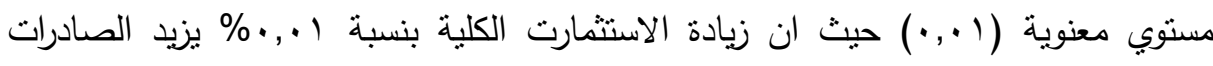

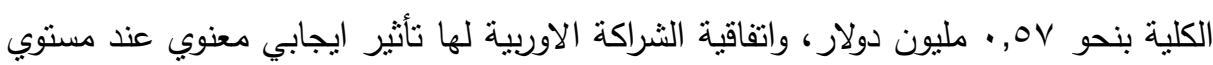

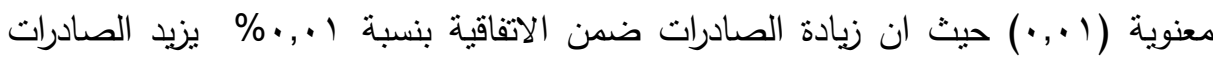

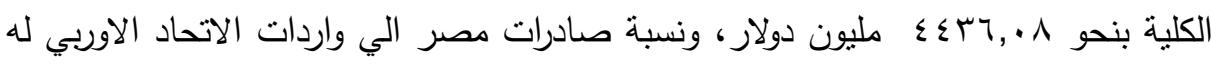

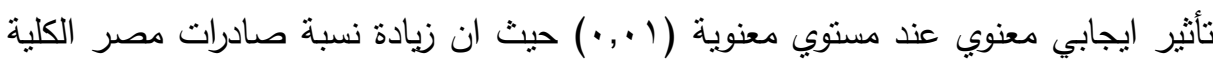

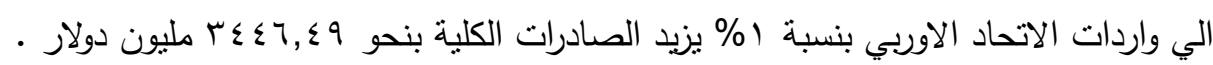


يشير جدول تطور اجمالي الصادرات الكلية رقم (V) وأهم المتغيرات الاقتصادية المؤثرة

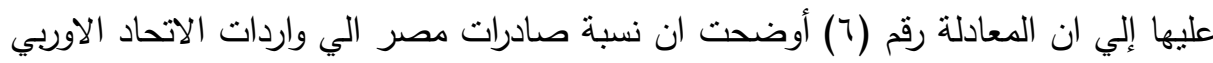

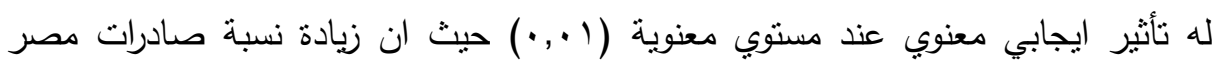

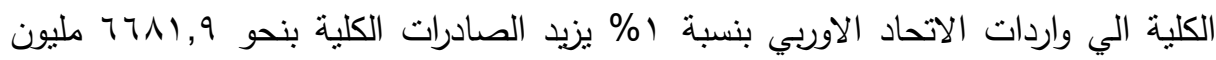

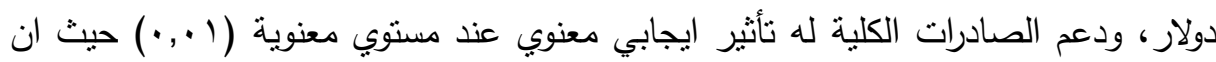

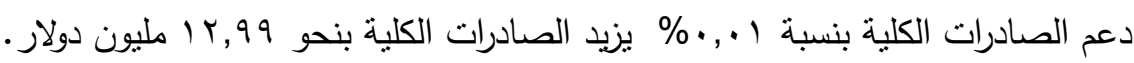

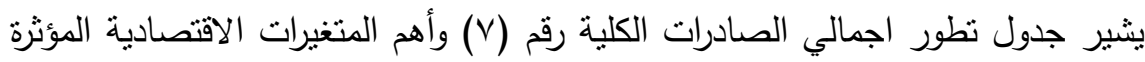

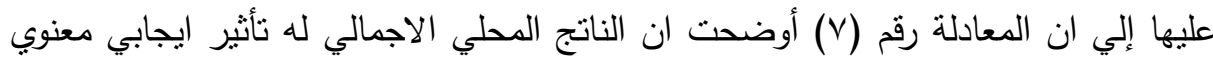

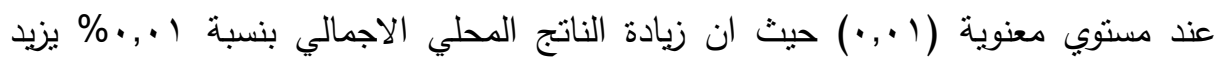

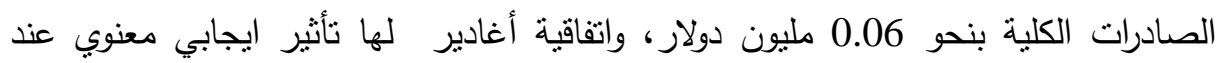

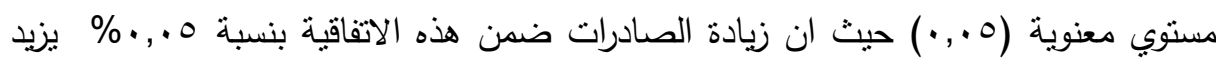

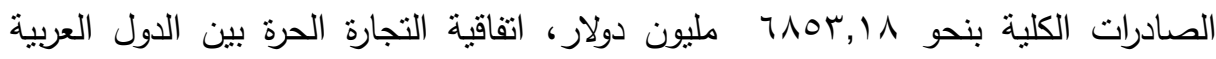
(تبسير) كان لها تأثثير ايجابي معنوي عند مستوي معنوية (1 (., •) حيث ان زيادة الصادرات

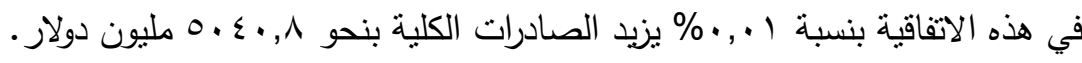

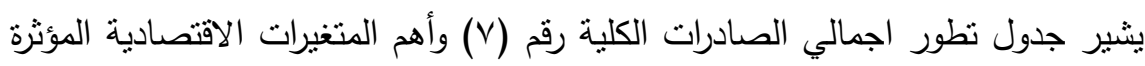

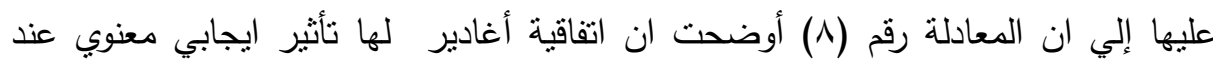

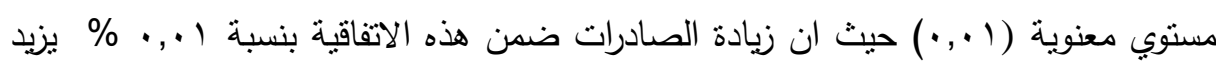

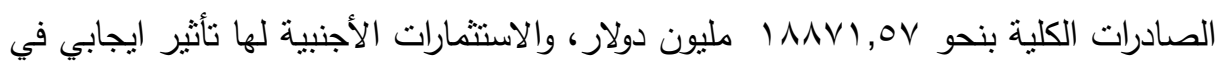
زيادة الصادرات الكلية عند مستوي معنوية (0., •) حيث ان زيادة الاستثمارات الاجنبية تزيد

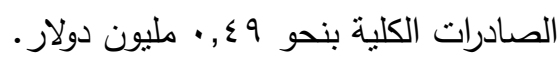
يشير جدول تطور اجمالي الصادرات الكلية رقم (V) وأهم المتغيرات الاقتصادية المؤثرة

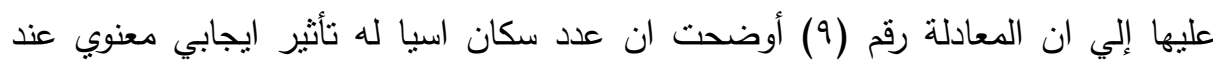

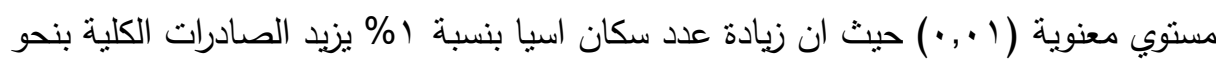

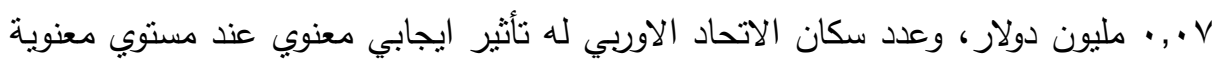


(1 +, •) حيث ان زيادة عدد سكان الاتحاد الاوربي بنسبة ا\% يزيد الصادرات الكلية بنحو

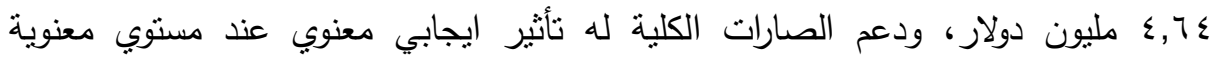

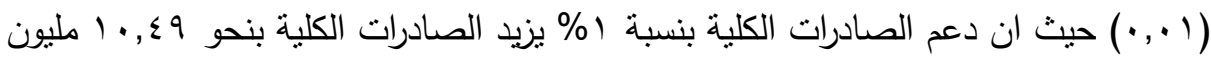

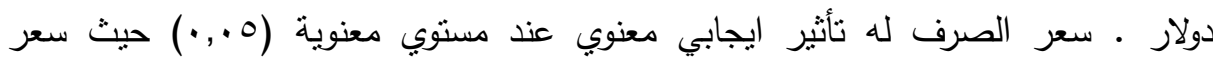

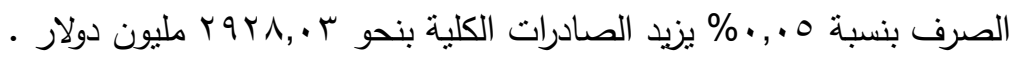

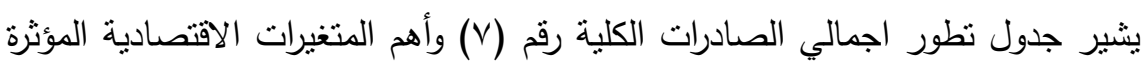
عليها إلي ان المعادلة رقم (• () أوضحت ان نسبة صادرات مصر الي واردات اسيا له تأثير ايجابي معنوي عند مستوي معنوية (1 (., ) حيث ان زيادة نسبة صادرات مصر الي واردات

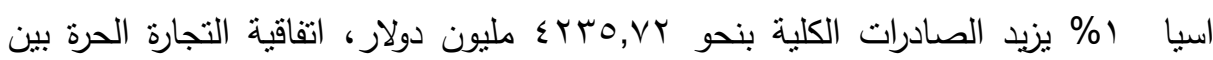

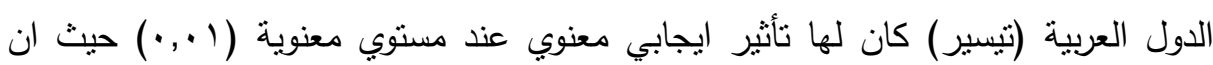

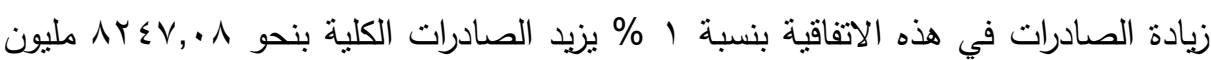

يشير جدول نطور اجمالي الصادرات الكلية رقم (V) وأهم المتغيرات الاقتصادية المؤثزة

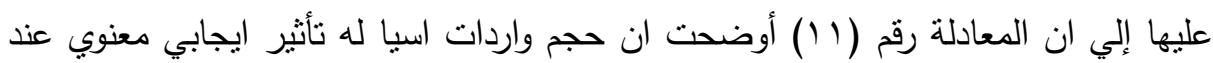

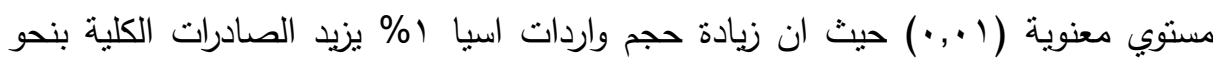

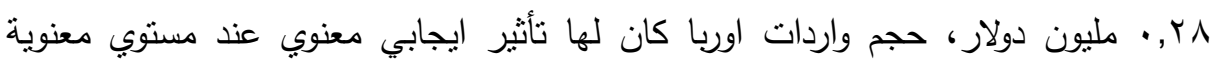

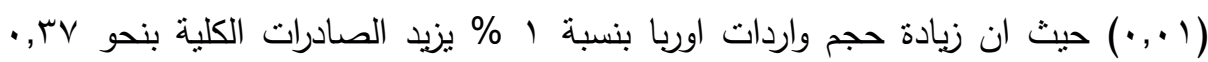

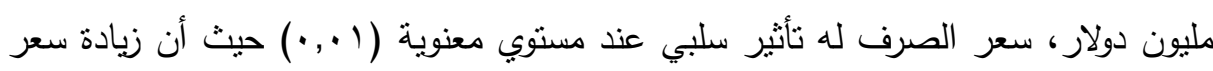

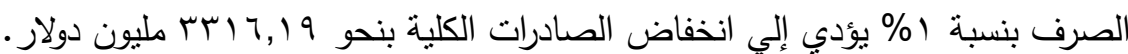

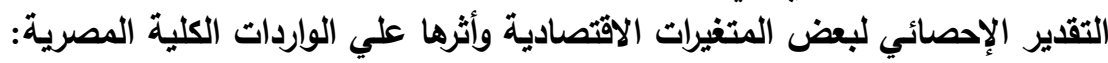

X2

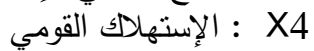

X6 X8

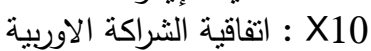

y2

X1

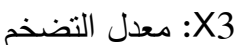

X5

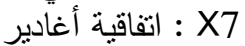
X9

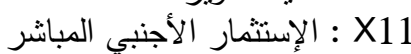

$$
\text { المجلد التاسع والثلاثون، الجزء الثالث، سبتمبر V V r r }
$$


يشير جدول (^) تطور اجمالي الواردات الكلية وأهم المتغيرات الاقتصادية المؤثرة عليها

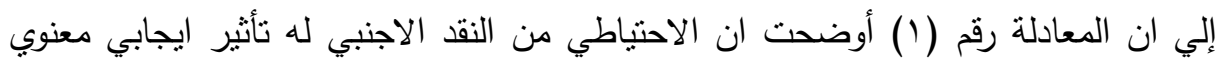

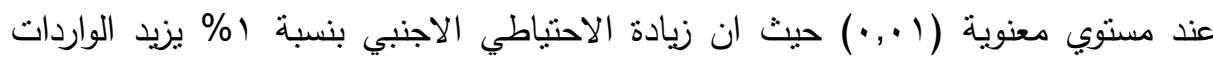

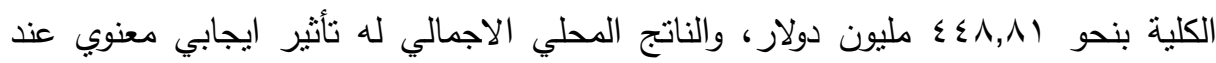

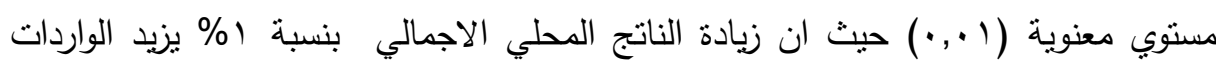
الكلية بنحو ^ץ, • مليون دولار.

يشير جدول نطور اجمالي الواردات الكلية رقم (^) وأهم المتغيرات الاقتصادية المؤثرة

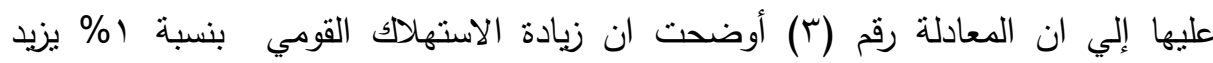
الواردات الكلية بنحو r r r r مليون دولار . يشير جدول نطور اجمالي الواردات الكلية رقم (^) وأهم المتغيرات الاقتصادية المؤثرة

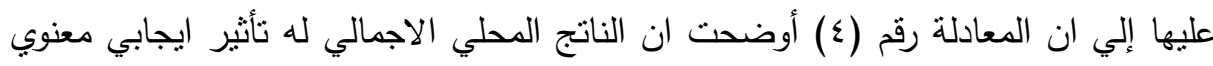

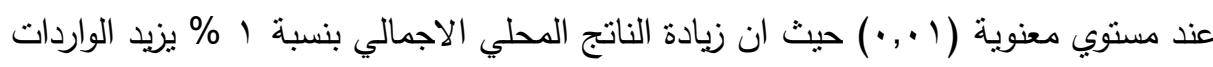

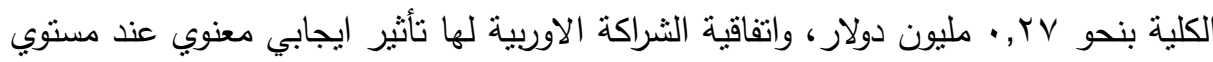

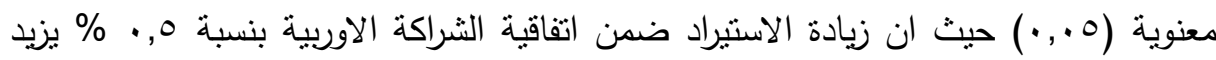

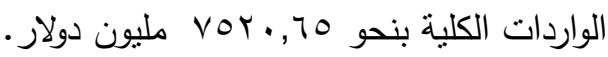


محمد كامل ريحان وآخرون

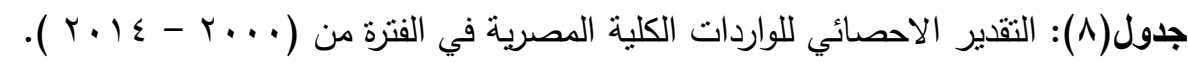

\begin{tabular}{|c|c|c|c|c|}
\hline $\mathbf{F}$ & $R \cdot 2$ & المعادلة & نوع المعادلة & رقمجم المعادلة \\
\hline$r_{1} \cdot, \vee, q * *$ & $\cdot, 9 \gamma$ & $\begin{array}{c}\mathrm{Y} 2=-18564.54+448.82 \times 5+0.28 \times 2 \\
(3.05) *(19.49) *\end{array}$ & backward & 1 \\
\hline $1 \mathrm{H}, \cdot T *$ & $\cdot, 97$ & $\begin{array}{c}Y 2=150.56+11028.58 \times 9+196.55 \times 4 \\
(2.09)^{*}(6.85)^{*}\end{array}$ & backward & r \\
\hline$r \cdot\urcorner, 00 *$ & $\cdot, 9 \varepsilon$ & $\begin{array}{c}Y 2=-1928.87+247.13 \times 4 \\
(14.372)\end{array}$ & stepwise & r \\
\hline $170,10 *$ & $\cdot, 9 \vee$ & $\begin{array}{c}Y 2=-12053.16+0.27 \times 2+7520.65 \times 10 \\
(13.98)^{* *}(2.21)^{*}\end{array}$ & stepwise & $\varepsilon$ \\
\hline $1 \varepsilon \cdot, 0\}$ & $\cdot, 91$ & $\begin{array}{c}Y 2=-201944.87+3214.71 \times 1 \\
(11.86)^{*}\end{array}$ & forward & 。 \\
\hline$r \varepsilon \cdot, \varepsilon \wedge *$ & $\cdot, 9 \wedge$ & $\begin{array}{c}\mathrm{Y} 2=3410.495+158.01 \times 4+18619.69 \times 7 \\
(6.49) *(4.15) *\end{array}$ & forward & 7 \\
\hline $11,09 *$ & $\cdot, 9 \vee$ & $\begin{array}{c}\mathrm{Y} 2=-152490-7183.07 \times 5+ \\
2887.34 \times 1 \\
(-2.51)^{*}(2.38)^{*}\end{array}$ & خطبة & $\gamma$ \\
\hline $1 Y, 19 *$ & $\cdot, \varepsilon \wedge$ & $\begin{array}{c}\mathrm{Y} 2=71.96+3996.44 \times 3 \\
(3.49)^{*}\end{array}$ & خطبة & $\wedge$ \\
\hline$r \gamma, \cdot \varepsilon * *$ & .,人ץ & $\begin{array}{c}Y 2=18908.84+54343.90 \times 8-3.32 \times 11 \\
(7.18)^{* *}(-3.3)^{* *}\end{array}$ & backward & 9 \\
\hline
\end{tabular}

المصدر: جُمعت وحُسبت من جدول رقم (ץ)،(؟) بالملحق

يشير جدول تطور اجمالي الواردات الكلية رقم (^) وأهم المتغيرات الاقتصادية المؤثرة

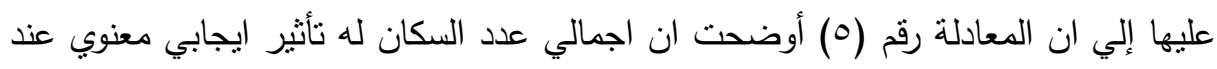

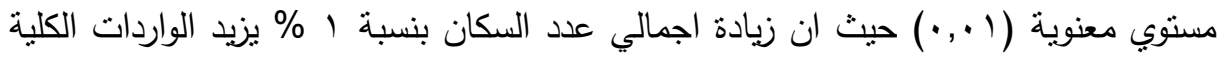

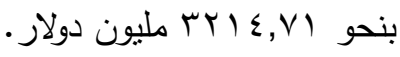

يشير جدول تطور اجمالي الواردات الكلية رقم (^) وأهم المتغيرات الاقتصادية المؤثرة

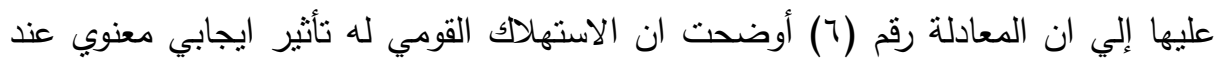
مستوي معنوية (1.,.·) حيث ان زيادة الاستهلالك القومي بنسبة ا $\%$ \% يزيد الواردات الكلية

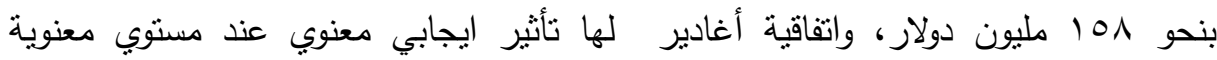

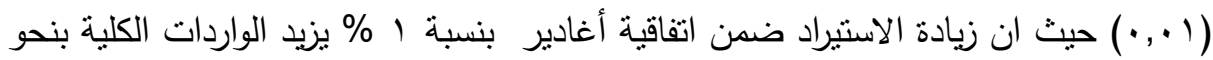

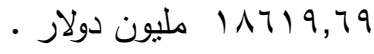


يشير جدول نطور اجمالي الواردات الكلية رقم (^) وأهم المتغيرات الاقتصادية المؤثرة عليها إلي ان المعادلة رقم (V) أوضحت اندير الن الاحتياطي من النقد الاجنبي له تأثنير سلبي

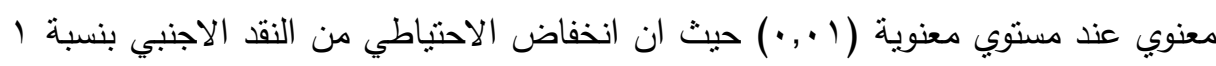

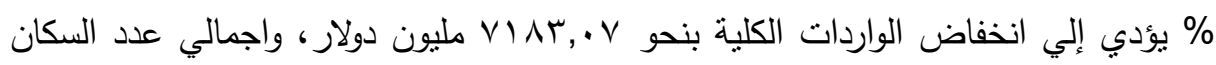

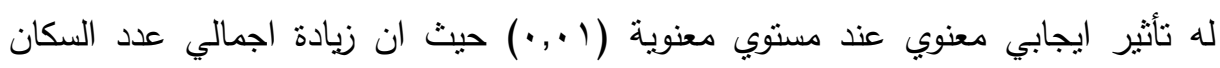

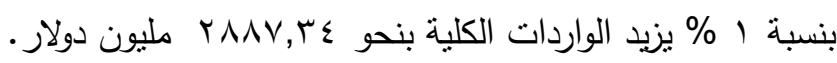

يشير جدول نطور اجمالي الواردات الكلية رقم (^) وأهم المتغيرات الاقتصادية المؤثرة

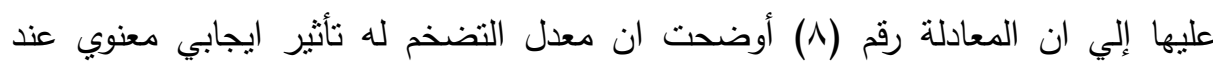

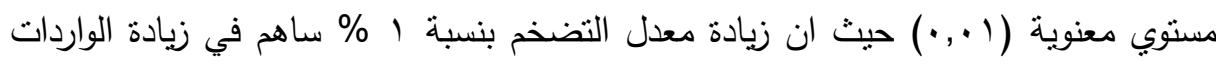

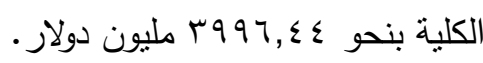

يشير جدول نطور اجمالي الواردات الكلية رقم (^) وأهم المتغيرات الاقتصادية المؤثرة

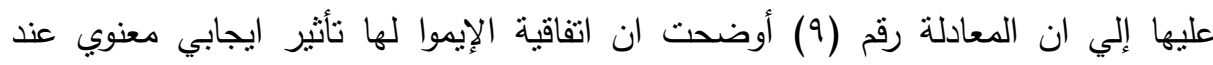

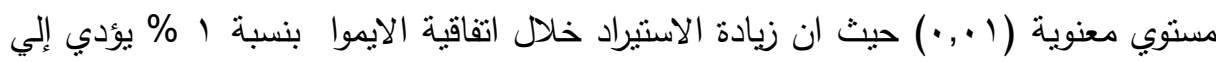

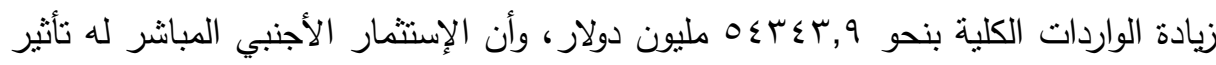

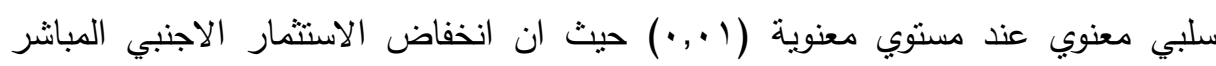

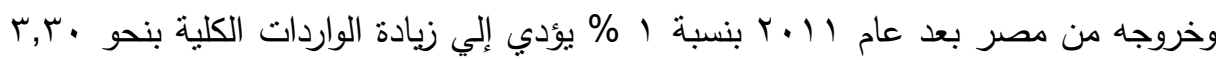
مليون دولار • مخروجه من مجن

\section{اللزوسياميت}

ا ـ إزالة المعوقات الإدارية والمالية وعدم تعدد الأجهزة والهيئات أى التعامل من خلال منفذ واحد

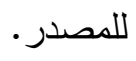

r. تحسين جودة المنتجات المصدرة.

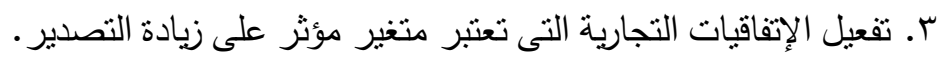

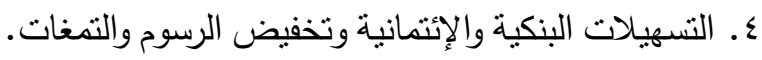


0. فتح أسواق جديدة، مع المحافظة على الأسواق الموجودة.

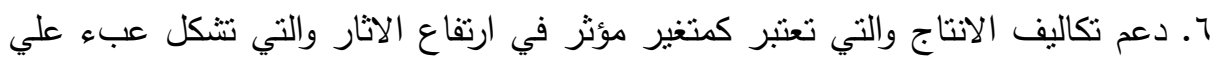

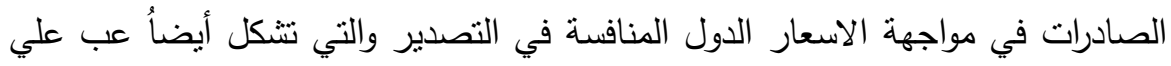

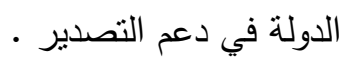

V. العمل علي زيادة الاستثمارات الصناعية والزراعية كتنغير يؤثر علي الصادرات والواردات

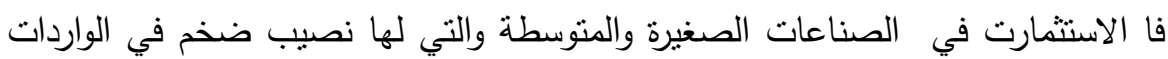
من هذه الصناعات يقلل الواردات منها ويخفف الضغط علي الميزان التجاري، وفي الانتاج الزراعي الاستثمار في زراعة محاصيل الاسنيراد والسلع الغذائية الأساسية لتقليل الفجوة منها ومن ثم تقليل الاستيراد منها ويخفف العجز من الميزان الزراعي.

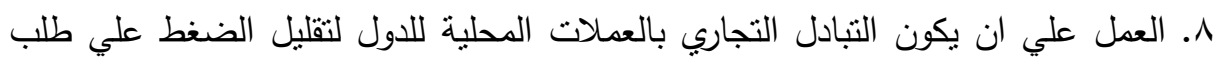

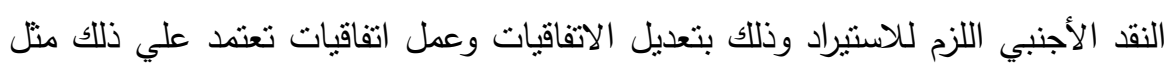

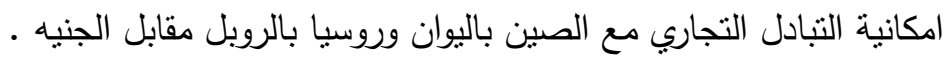
9. الحد من الاستيراد بمنع استيراد السلع المنتجة محلياً. • 1. تقليل الاستهلاك القومي من بعض السلع غير الأساسية والتي تشكل متغير مؤثر علي

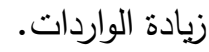

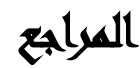

الجهاز المركزي للتعبئة العامة والإحصاء - قاعدة بيانات التجارة الخارجية

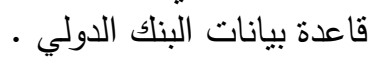

قاعدة بيانات وزارة التخطيط ـ النيان. تقارير البنك المركزي - أعداد متفرقة . عاطف جودة، محاضرات في التجارة الدولية، جامعة عين شمس، كلية الزراعة، قسم الاقتصاد

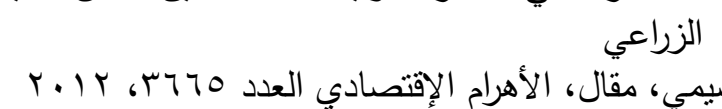

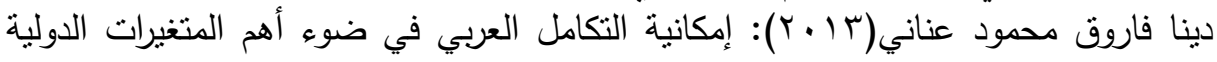

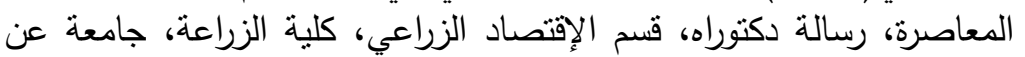




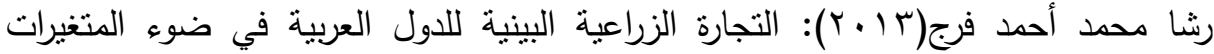

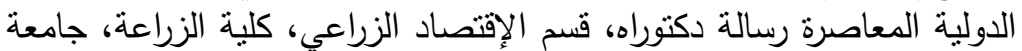

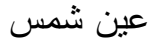

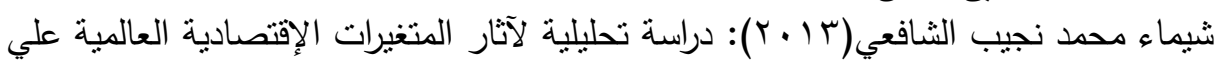
الصادرات الزراعية المصرية، رسالة ماجستير، قسم الاقتصاد الزراعية الزاعي، كلية

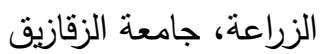

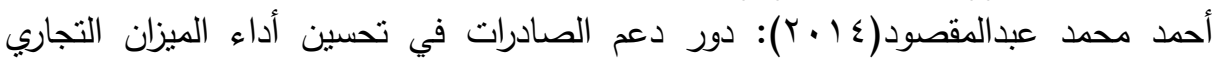

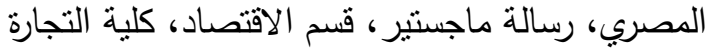

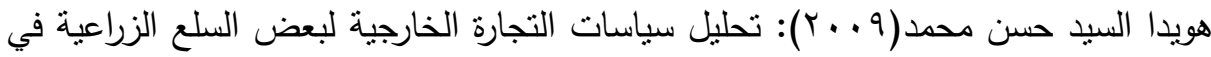

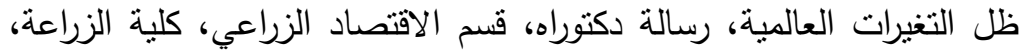

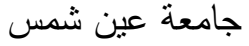

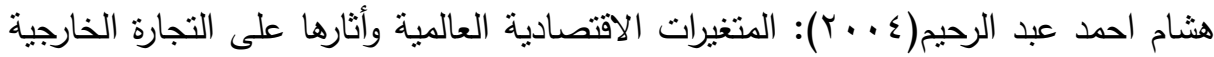

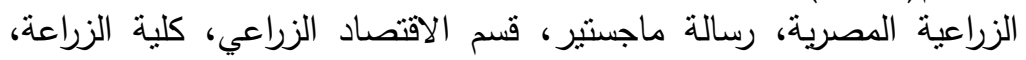

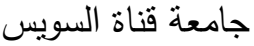

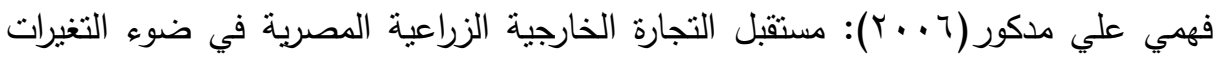

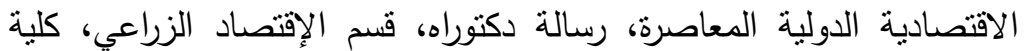

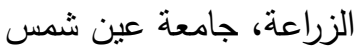

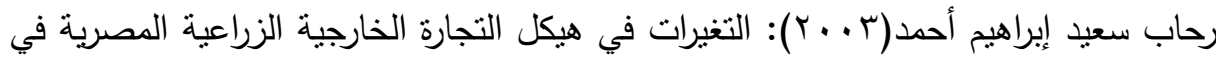

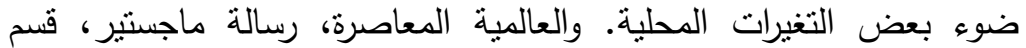

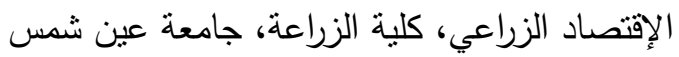

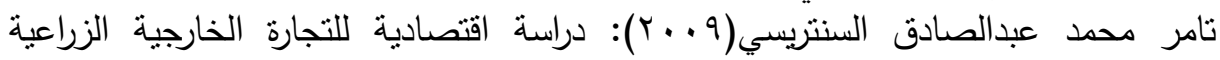

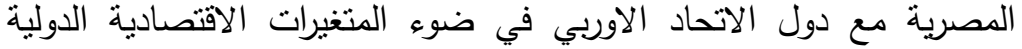

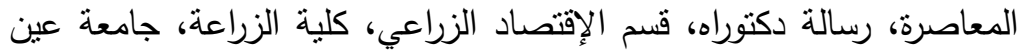

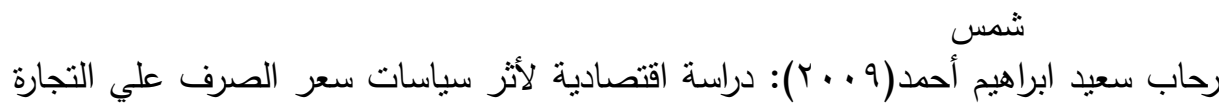

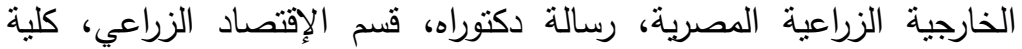
الزراعة، جامعة عين شمس الزعة العمرة

Azharia Abdelbagi Elbushr" The role of COMESA in promoting intraregional agricultural trade: Case study of Sudan " article.

A new Perspective Based on TFP growth structure " article.

Pattern: evaluation and alerts" article 


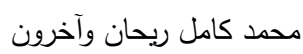

\title{
THE EFFECT OF ECONOMIC CHANGES IN EGYPT ON THE EXTERNAL TRADE
}

Rehan, M. K. ${ }^{(1)}$; Abd El-Hameed, Seham, ${ }^{(2)}$; A Refaat, A. A. ${ }^{(3)}$; Ghazala, Azza, M. A. ${ }^{(3)}$ and Fahmy, W. M. ${ }^{(3)}$

1) Faculty of Agriculture, Ain Shams University 2) Institute of Environmental Studies \& Research, Ain shams University. 3) Desert Research Center.

\begin{abstract}
The foreign trade sector plays an important role in the economic development process especially in the developing countries. The development of Egyptian foreign trade is closely related to economic events and changes. It helps to achieve local market balances and increase national income in the event of a high rate of exports and reduction of imports.

The problem of the study is that there are many problems facing foreign trade. In recent years, there have been many economic changes at the local level. These variables have had some effects on foreign trade and the trade balance.

The study aims to identify the most important economic variables that affect foreign trade and identify the most important effects of economic changes on Egyptian exports and imports and ways of dealing with them, which can contribute in guiding trade policy to increase exports and reduce imports to reduce trade deficit.

The research indicated that the total Egyptian exports to the world countries increased by LE 15,232.18 million and achieved the largest value of Egypt's total exports to the group of Western European countries, reaching about 3853.6 million pounds annually. The research found that the value of total exported exports to the world countries , Which reached about $57.1 \%$ in 2000 and improved in 2009, which reached about $0.2 \%$. The research found that the total value of total
\end{abstract}

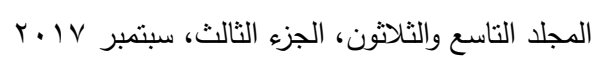


imports to Egypt from the world countries was not stable, as it reached about $70 \%$ in 2000 and this coefficient improved in 2011 by about $2.3 \%$ The research referred to the statistical estimation of some of the multiple regression models (Forward, Stepwise, Forward), where it was proved that the economic variables that have a positive effect on the total Egyptian exports are the exchange rate in various equations for the various regression models. The increase in the exchange rate helps to increase the total Egyptian exports as well as the export support variable and the total investment variable. Where the equations of multiple regression models showed in various ways that the increase in export support and total investment help increase the total Egyptian exports. The research also proved that the economic variables that have a positive effect on the total Egyptian imports are the national consumption, The increase in national consumption helps to increase the total Egyptian imports as well as the variable population and the variable foreign exchange reserves. The equations of multiple regression models have shown in various ways that increasing national consumption and foreign exchange reserves help increase the total Egyptian imports. 